\title{
The role of smalt in complex pigment mixtures in Rembrandt's Homer 1663: combining MA-XRF imaging, microanalysis, paint reconstructions and OCT
}

\author{
A. van Loon ${ }^{1,2,3^{*}}$ (D, P. Noble ${ }^{1}$, D. de Man ${ }^{4}$, M. Alfeld ${ }^{3}$, T. Callewaert ${ }^{3}$, G. Van der Snickt ${ }^{5,6}$,, K. Janssens ${ }^{5}$ and J. Dik ${ }^{3}$
}

\begin{abstract}
As part of the NWO Science4Arts REVISRembrandt project (2012-2018), novel chemical imaging techniques were developed and applied to the study of Rembrandt's late experimental painting technique (1651-1669). One of the unique features in his late paintings is his abundant use of smalt: a blue cobalt glass pigment that he often combined with organic lake pigments, earth pigments and blacks. Since most of these smalt-containing paints have discolored over time, we wanted to find out more about how these paintings may have originally looked, and what the role of smalt was in his paint. This paper reports on the use of smalt in complex pigment mixtures in Rembrandt's Homer (1663), Mauritshuis, The Hague. Macroscopic X-ray fluorescence imaging (MA-XRF) assisted by computational analysis, in combination with SEM-EDX analysis of paint cross-sections, provides new information about the distribution and composition of the smalt paints in the painting. Paint reconstructions were carried out to investigate the effect of different percentages of smalt on the overall color, the drying properties, translucency and texture of the paint. Results show that the influence of (the originally blue) smalt on the intended color of the paint of the Homer is minimal. However, in mixtures with high percentages of smalt, or when combined with more transparent pigments, it was concluded that the smalt did produce a cooler and darker paint. It was also found that the admixture of opaque pigments reduced the translucent character of the smalt. The drying tests show that the paints with (cobalt-containing) smalt dried five times faster compared to those with glass (without cobalt). Most significantly, the texture of the paint was strongly influenced by adding smalt, creating a more irregular surface topography with clearly pronounced brushstrokes. Optical coherence tomography (OCT) was used as an additional tool to reveal differences in translucency and texture between the different paint reconstructions. In conclusion, this study confirmed earlier assumptions that Rembrandt used substantial amounts of smalt in his late paintings, not for its blue color, but to give volume and texture to his paints, to deepen their colors and to make them dry faster.
\end{abstract}

Keywords: Rembrandt, Painting technique, Smalt, Macroscopic X-ray fluorescence imaging, t-SNE plots, SEM-EDX, Optical coherence tomography, Paint reconstructions

\footnotetext{
*Correspondence: a.van.loon@rijksmuseum.nl

${ }^{1}$ Conservation \& Science, Rijksmuseum, Hobbemastraat 22, 1071

ZC Amsterdam, Netherlands

Full list of author information is available at the end of the article
}

\begin{abstract}
Introduction
Use of smalt in Rembrandt's late works

Rembrandt's late works, which date from the 1650s and 1660 s, are characterized by their loose, sketchy appearance, lively brushwork and unusual surface roughness. Some of the technical aspects-described in the seventeenth century as 'the rough manner'-are also to be
\end{abstract}


found even in his earliest works [1, 2]. Clearly, Rembrandt did not comply with the change in taste that took place in the second half of the seventeenth century, when fine handling of the paint and smooth surfaces were more highly appreciated than this rough manner. As a result Rembrandt's late works differ radically from the polished works of most Dutch painters from this period. One of the unique features of Rembrandt's late works is the use of large amounts of smalt: a potash-silica glass colored blue with cobalt [3-5]. Smalt was widely used in the seventeenth century as an inexpensive substitute for the costly ultramarine. The pigment was available in different grades, from pale gray to deep blue, with the color being dependent on the particle size and cobalt content [6].

In many cases, Rembrandt mixed the smalt with lakes, earths and black pigments, so his intention was not to create a primarily blue paint. Smalt, unfortunately, is very unstable in oil media. Discoloration of smalt particles is a direct result of depletion of potassium out of the glass and incorporation of water molecules $[7,8]$. The cobalt (II) ions in the glass change from a tetrahedral coordination (strong blue) to an octahedral coordination state (colorless). In addition to the loss of color in the pigment itself, there is associated browning of the paint matrix and surface blanching (crust formation) that occurs due to the formation of potassium soaps from the reaction with fatty acids in the drying oil medium [6]. Because the smalt paints in Rembrandt's paintings have severely discolored over time-we can now prove that Rembrandt originally used a blue smalt, and not a colorless or nearly colorless smalt/glass, as has been suggested in the past [ 9 ,
10], it is still unclear what the artist's intention and the role of smalt were in these complex paint mixtures. Different researchers have formulated hypotheses on the function of smalt in Rembrandt's late paintings [1, 5, 9, 11]. Since smalt has a poor hiding power it seems likely that it was added to paint mixtures for reasons other than its blue color. It is known to be a good surface drier due to the presence of cobalt. Furthermore it may have been added to create certain painterly effects. Because of its low refractive index (1.46-1.52), close to that of the oil medium, adding smalt can make a paint that is more translucent, at the same time deepening its color. It is also possible that Rembrandt added coarse smalt to his paints as a bulking agent to create volume and texture. In order to gain more insight into the role of smalt in Rembrandt's paint mixtures-specifically how it affects their optical and handling properties-we have taken the research a step further in this paper by combining analysis of the smalt-containing paints in Rembrandt's Homer (1663, Mauritshuis, The Hague) with paint reconstructions, with the aim of getting a better understanding of Rembrandt's original intentions.

\section{Rembrandt, Homer, 1663}

Rembrandt's Homer, painted in 1663 for Don Antonio Ruffo's collection in Messina (Sicily), depicts the blind Homer dictating his verses (Fig. 1). He is seen seated, holding a staff in his left hand. Unfortunately the spatial illusion in the painting is severely compromised by the deterioration of the smalt paints. The thickly applied light paint areas of his face, his right hand, and
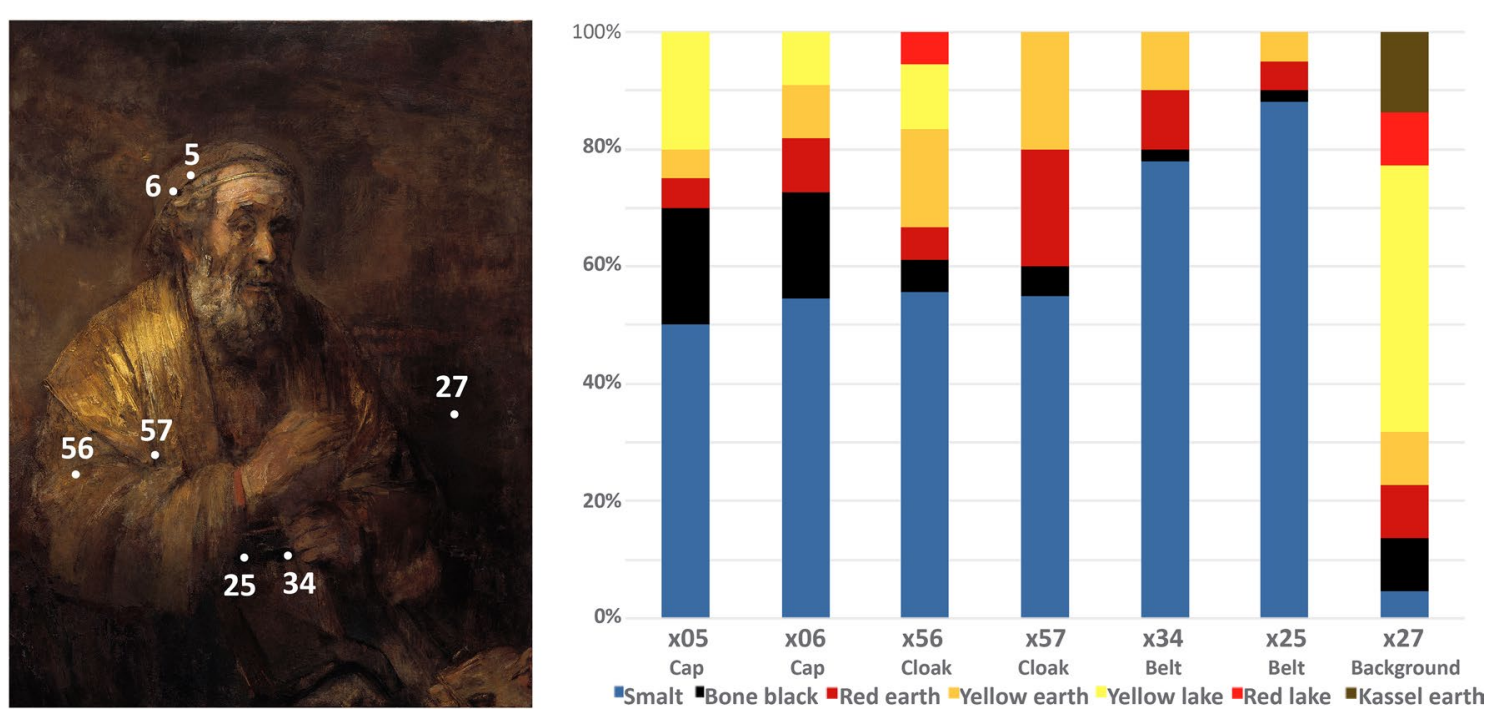

Fig. 1 Sample locations of the seven paint cross-sections from various smalt paints in the painting (left), and chart showing proportions (vol\%) of the pigments identified in the cross-sections (right). The composition of each of these smalt paints was used to make the paint reconstructions 
the golden-yellow of the shawl around his shoulders are the best preserved. The rest of Homer's garment and his cap, however, now appear an almost monochrome brown with most of the detailing having being lost. These areas show little contrast with the background, which is also brown.

Originally the painting was much larger, approximately $180 \times 140 \mathrm{~cm}$, and included two scribes in the lower right, at Homer's feet. All that remains of the figures are two fingers holding a pen and the top of the inkpot. That a part of the composition has been lost, is most likely a result of the 1783 earthquake in Messina, which damaged the Ruffo family palace where the painting had been kept since 1664 [12-14]. The painting was treated in the Mauritshuis conservation studio in 2005-2006. Research at the time focused on the identification and interpretation of the whitish surface layer that covered most of the dark areas of the painting. Paint sample analysis demonstrated that this layer contained degradation products associated with the underlying smalt-rich paint. The crust was found to consist mostly of lead, potassium and sulfur in the form of sulfates of lead (anglesite) and lead-potassium (palmierite), the lead and potassium originating from the paint and ground layers below, and the sulfur from an external source, such as sulfur dioxide $\left(\mathrm{SO}_{2}\right)$, a well-known air pollutant $[3,15]$.

\section{Research goals}

To gain more insight into the distribution of smalt in the painting, macroscopic X-ray fluorescence imaging (MAXRF) of the entire painting was carried out in 2012 as part of the NWO Science4Arts Project REVISualizing late Rembrandt. This provided new information about the use and distribution of smalt in the painting. This technique analyzes the chemical elements in the paint in a non-invasive manner, and detects signals of cobalt (Co) from the smalt pigment, and nickel $(\mathrm{Ni})$ and arsenic (As) associated with the cobalt ore. The principle cobalt ore used in the manufacture of smalt at the time was smaltite ([Co, Ni] $\left.\mathrm{As}_{3-2}\right)$, but in the seventeenth century, erythrite $\left(\left[\mathrm{Co}, \mathrm{Ni}_{3}[\mathrm{AsO} 4]_{2} \cdot \mathrm{H}_{2} \mathrm{O}\right)\right.$ and cobaltite $((\mathrm{Co}, \mathrm{Fe}) \mathrm{AsS})$ were probably also used [16]. The combined presence of $\mathrm{Co}, \mathrm{Ni}$ and As is considered a good marker of smalt, even when the pigment is very degraded $[4,17]$. In addition to manual visual evaluation, the MA-XRF set of data was also analyzed with advanced computational techniques. T-Stochastic Neighbor Embedding (t-SNE) was used to identify clusters of similar elemental composition in the painting [18], while scatter plots of $\mathrm{Co}$ and $\mathrm{Ni}$ or Co and As can reveal the potential use of more than one type of smalt [17]. Light microscopic examination and SEM-EDX analysis of paint cross-sections taken during the treatment in 2005-2006 helped establish the build-up and composition of the smalt layers. Apart from smalt, the paints were found to contain red earth, yellow earth, Kassel earth, red lake, yellow lake, and/or bone black in different proportions. The smalt particles were also characterized using quantitative EDX analysis.

Based on the analysis of the smalt paints in Homer, we designed a series of experiments and made paint reconstructions to investigate the effect of different proportions of smalt on the color, drying properties, translucency/hiding power and texture of the paint. Paint mixtures were prepared using historically appropriate materials: a smalt that best matched the composition and size of smalt used by Rembrandt (potash glass with 2.66 wt $\% \mathrm{CoO}$; variable particle size up to $60 \mu \mathrm{m}$ ). These were compared with a paint mixture containing colorless glass (0 wt\% $\mathrm{CoO}$ ), a paint with more intense blue smalt with higher Co content $(4.0 \mathrm{wt} \% \mathrm{CoO})$, and a paint without smalt or glass. The three qualities of smalt, as well as the yellow and red lake pigments used for the paint reconstructions were fabricated according to historical recipes, to reproduce the characteristics of the pigments in Rembrandt's paint mixtures as closely as possible. Furthermore, optical coherence tomography (OCT) was applied as an additional visualization and evaluation technique on a selection of the reconstructed paints. This non-invasive imaging modality typically uses low coherent nearinfrared light, which allows penetration of translucent paints and capture of high-resolution depth profiles of layered structures [19-22]. In our study, OCT was particularly useful for showing differences in translucency and texture when the paint reconstructions containing smalt were compared to those without smalt. To conclude this paper, the results of the paint reconstructions are discussed in the context of Rembrandt's late painting technique and how he manipulated his paints to create certain painterly effects.

\section{Experimental}

\section{Macroscopic X-ray fluorescence imaging (MA-XRF)}

MA-XRF maps were collected using the Bruker M6 Jetstream prototype [23]. The instrument consists of a measuring head equipped with a $30 \mathrm{~W}$ Rhodium-target microfocus X-ray tube, a polycapillary lens, and a $30 \mathrm{~mm}^{2}$ XFlash silicon drift detector (SDD) with beryllium window (energy resolution $<145 \mathrm{eV}$ at $\mathrm{Mn}-\mathrm{Ka}$ ), that is mounted on a $80 \times 60 \mathrm{~cm} \mathrm{XY} \mathrm{motorized} \mathrm{stage.} \mathrm{The}$ Homer painting, measuring $107 \times 82 \mathrm{~cm}$, was scanned in a total of four scans. Scans were carried out at $35 \mathrm{kV}$, a current of $500 \mu \mathrm{A}$, a $500 \mu \mathrm{m}$ step size, and a $20-25 \mathrm{~ms}$ dwell time. The distance between the scanning head and the paint surface was set at c. $1 \mathrm{~cm}$, corresponding to an $\mathrm{X}$-ray spot size of c. $300 \mu \mathrm{m}$. All data were collected with the Bruker M6 Jetstream software package. The acquired 
data cubes were then exported and processed using PyMca [24] and the in-house developed Datamuncher software to produce the elemental distribution maps [25].

In order to identify areas with similar pigment composition, t-Stochastic Neighbor Embedding (t-SNE) was used to cluster (group) pixels of similar XRF signals together. After fitting the XRF data 18 elemental distribution images were found that contained relevant information. Comparing these 18 images manually is challenging, but we can consider each pixel also as a point in an 18-dimensional space. The pixels with similar signals form local "neighborhoods", where they have a short Euclidean distance to their respective neighbors. As we cannot visualize the 18-dimensional space, we need to find a representation of our data that allows us to project it into a two-dimensional plane with a minimal loss of information. An accurate representation of all aspects of the 18-dimensional data is not possible, so we need to use one that preserves the most relevant information. This information is for chemical clustering the preservation of local neighborhoods. t-SNE achieves this by clustering points with similar elemental profile closely together, but does not attempt to move points that differ far away from these points, but just outside their local neighborhood that appears as a cloud in the scatter plot. An example for this is the dark red Lead Tin Yellow cluster in Fig. 3c. From the scatter plot we can assume that this point cloud represents points with at least one feature different from the main cloud, a strong Sn-L signal. This allows us to cluster them. However, we cannot quantify the distance in the scatter plot and we can also not quantify the distance of this point cloud to the main cloud. There is an empty space without points that indicates a boundary, but it cannot be quantified. In the same way, the borders of clusters in the main cloud are indicated by areas of reduced point density, indicating that these neighborhoods are not fundamentally different. The selection of the clusters was an iterative manual process. First, a cluster was manually drawn in the t-SNE scatter plot through the areas of lower point density. The resulting distribution of the cluster in the image was then compared to the elemental distribution images. If the cluster represented areas with clearly different elemental profiles the cluster was reduced in size until a meaningful chemically homogenous representation was found. The precise mathematical background is explained in [18]. In the data set, $10 \times 10$ pixels were averaged into a single new pixel, to enhance statistics and to reduce the processing time. With a perplexity of 30 , the data converged in 2000 iterations after $20 \mathrm{~min}$ on a high end 2018 laptop.

For a clear visualization of two different groups of smalt in the painting, two components were selected in a Co:Ni scatter plot, and every pixel was expressed as a non-negative linear combination of these two components. Both clustering approaches made use of the python module scikit-learn (version 0.19.1) and were implemented in an open source GUI Data Handler P [26], which was developed for a previous project [27].

\section{Paint cross-section analysis \\ Sample preparation and light microscopy}

Microscopic paint samples were collected from different smalt-containing areas during treatment of the painting in 2005-2006. The paint samples were embedded in Easy Sections (VWFecit, UK) using Poly-pol PS230 polyester mounting resin with M.E.K.-peroxide harder (Poly-Service, Amsterdam, Netherlands) and polished with Micromesh sheets up to grade 12,000 (Micro-Surface Finishing Products Inc., Wilton, Iowa, USA), to expose a cross-section of the paint layer build-up. The embedded samples were first examined using a Leica DM2500 light microscope equipped with a Leica DFC490 digital camera, at magnifications up to 1000 times, in bright field, dark field, and ultraviolet (UV-A).

\section{Scanning electron microscopy coupled with energy dispersive $X$-ray analysis (SEM-EDX)}

The paint cross-sections were gold coated $(3 \mathrm{~nm})$ on a SC7640 sputter coater (Quorum Technologies, Newhaven, East Sussex, UK) to improve surface conductivity. The samples were analyzed using either a FEI XL30 SFEG or a FEI Verios 460 high-pressure electron microscope, at an acceleration voltage of $20 \mathrm{kV}$ and a beam current of $0.20 \mathrm{nA}$. The XL30 SFEG was equipped with an EDAX EDX system, while the Verios 60 was equipped with an Oxford EDX system, to yield elemental composition of the pigments within the paint layers.

\section{Series of paint reconstructions Design of the paint reconstructions}

We selected seven cross-sections from four different smalt-containing areas of the painting: Homer's garment, his cap, his belt, and the background. From the cross-sections we calculated the proportions of the pigment particles (in vol\%, as compared to the rest of the pigments in the surface layer) in the samples from the light microscopic images and EDX maps using the open source software package ImageJ (Fig. 1). This information formed the basis for the paint reconstructions. We prepared the same paint mixtures with colorless glass $(0 \mathrm{wt} \%$ $\mathrm{CoO}$ ), and with two qualities of blue smalt (2.66 and 4.0 $\mathrm{wt} \% \mathrm{CoO})$. The pigments were ground in oil by hand on a glass slab using a muller, and then mixed in the determined proportions. The paints were applied on glazed black and white ceramic tiles with a wet film thickness of $100 \mu \mathrm{m}$ using a drawdown bar (a stainless steel applicator 
with gap clearances on 4 sides; film width is $60 \mathrm{~mm}$ ). We also applied paint films of the pure pigments as a reference. Color measurements were carried out on the dried paint films (see "Color measurements" section). The difference in $L^{*} a^{*} b^{*}$ values between the paints on the black and white tiles was used as a measure of translucency of the paint following the method described by Shimazu [28]. For the drying tests, the same paint mixtures were applied on black and white sealed opacity charts (Form 2A Opacity Charts, Leneta Company, Mahwah, NJ, USA) with a wet film thickness of $50 \mu \mathrm{m}$. The drying speed of the different smalt paint-outs was tested using fine table salt (see "Salt drying test" section). We also made a series of paints based on the same pigment mixture (yellow earth, red earth, bone black), but with varying amounts of smalt, $0,25,50$ and $75 \%$ of the total pigment volume, to study their effect on the paint texture. These were painted out with a broad hog-hair brush on commercially prepared canvas boards. OCT was performed on a selection of the paint-outs as a way of investigating the effect of smalt on the translucency and surface topography of the paint (see "Optical coherence topography (OCT)" section).

\section{Materials used for the paint-outs}

Oil medium, earth pigments and bone black Raw linseed oil was provided by Art Proano Gaibor, scientist at the Cultural Heritage Agency of the Netherlands (RCE). This oil is pressed from organic linseed in windmill the Pink in Zaanstad, The Netherlands. The yellow earth (color index: PY 43.77492), red earth (color index: PR 102.77491), Kassel earth (color index: $\mathrm{NBr} 8$ ), and bone black (color index: PBk 9.77267) were commercially obtained from Kremer Pigmente (Germany)

Synthesis of colorless potash glass and blue smalts The colorless potash glass and the two types of smalt were prepared by melting 72 grams quartz $\left(\mathrm{SiO}_{2}\right.$, Keramikos, Haarlem) and $21 \mathrm{~g}$ potassium carbonate $\left(\mathrm{K}_{2} \mathrm{CO}_{3}\right.$, Keramikos, Haarlem) in a crucible for $8 \mathrm{~h}$ at $1200{ }^{\circ} \mathrm{C}$ in a ceramic oven, imitating the historical production of smalt [29]. For the colorless glass no cobalt oxide $(\mathrm{CoO})$ was added, but for the two smalts 2.66 and 4 grams $\mathrm{CoO}$ (Keramikos, Haarlem) were added to the dry $\mathrm{SiO}_{2}$ and $\mathrm{K}_{2} \mathrm{CO}_{3}$ powders to obtain a 2.66 and a 4 wt $\% \mathrm{CoO}$ smalt with c. 16 wt $\% \mathrm{~K}_{2} \mathrm{O}$ (we simplified the recipe slightly by only adding cobalt oxide and omitting the trace amounts of oxides of arsenic, nickel etc. normally present in historic smalts, although we are aware these have an influence on the optical properties). The melted products were milled with a stone mortar; a particle size of below $60 \mu \mathrm{m}$ was obtained by mechanical sieving.
Synthesis of red and yellow organic lake pigments Madder lake on a hydrated alumina substrate and buckthorn lake on a mixed substrate containing hydrated alumina and calcium salts were prepared according to recipes WL-Al-Ch and ML-Std described by Kirby et al. [30]. The raw materials used for making the lakes-the madder root, unripe buckthorn berries and potash alum-were obtained from Kremer Pigmente (Germany).

\section{Color measurements}

The color measurements were carried out on a dense spot of the dried paint film using a Konica Minolta photospectrometer CM-2600d/2500d (light source D65, $10^{\circ}$ observer, $8 \mathrm{~mm}$ aperture, CIELAB1976 color space). Data are expressed as $L^{*} a^{*} b^{*}$ values with the specular component excluded, in which $\mathrm{L}^{*}$ is defined as the lightness, $a^{*}$ the red or green value and $b^{*}$ the yellow or blue value. Digital color images were created by entering the $\mathrm{L} * \mathrm{a} \mathrm{b}^{*}$ values in Photoshop to give a visual impression of the color.

\section{Salt drying test}

The salt drying test, developed by the Federal Art Project of the Works Progress Administration for Massachusetts [31], is based on the principle that the wetter the paint is, the more salt will stick on it. One gram of fine table salt $(\mathrm{NaCl})$ was strewn over the drying paint under an angle of $45^{\circ}$, at different time intervals, starting at $0 \mathrm{~h}$ and ending after 10 days. The charts were weighed before and after the salt was strewn to calculate the amounts of sand absorbed/taken up by the wet paint, which was used as a measure of their drying speed.

\section{Optical coherence topography (OCT)}

The OCT experiments were performed on paint films of pure pigment (smalt, madder, yellow earth) and on paint reconstructions based on sample x34 (Fig. 1) with and without smalt/glass, using a Thorlabs Ganymede-II-HR spectral-domain OCT system. The computer is a Dell precision workstation (T1700) with 16 GB Ram memory and an Intel Xeon E3-1271v3 cpu. The OCT system has a spectrum centered at $900 \mathrm{~nm}$, spanning a bandwidth of $195 \mathrm{~nm}$. The specified axial bandwidth limited resolution is $3.0 \mu \mathrm{m}$ (in air). The spectrometer roll-off is measured and fitted to the theoretical relation $\sim$ from Nassif [32] resulting in a spectral resolution $\Delta \mathrm{k}$ over sampling interval $\delta \mathrm{k}$ ratio of $\omega=0.69 \pm 0.05$. The signal to noise ratio, determined from an OCT measurement of a single mirror reflector at $0.3 \hat{\mathrm{A}} \mu \mathrm{m}$ depth, is $92.4 \pm 0.5 \mathrm{~dB}$ and the used imaging lens is a Thorlabs LSM04-BB telecentric lens. A cross-sectional image of the paint film was 
produced by scanning the beam across the sample, commonly known as B-scan. The images were not corrected for refractive indices of the components present within the paint: vertical scales represent optical (not geometrical) distances.

\section{Results and discussion}

\section{MA-XRF elemental distribution maps}

The entire painting was imaged in four scans. Figure 2 shows the most informative elemental distribution maps (displayed as linear gray-scale images) next to the visible light image. The description below is based on manual visual comparison of the elemental maps. Additional computational analysis using t-SNE recognized 18 different clusters in the painting with similar elemental compositions, most of which had also been recognized by manual visual comparison. These clusters are highlighted in Fig. 3. Although t-SNE may not yield many new insights when compared to a manual visual interpretation of the elemental distribution maps, it is very useful in reducing all the information of the maps into one easily readable representation.

The cobalt K-line map reveals the abundant distribution of smalt in the painting (Fig. 2b, light areas). The nickel (Fig. 2c) and arsenic maps (arsenic map not shown) overlap with the cobalt map, and therefore can be associated with the presence of smalt. We see that smalt is present in Homer's entire brown cloak and undergarment, and particularly, in his cap (green cluster in Fig. 3c) and belt (dark blue cluster in Fig. 3b) shown by the high Co signals in the Co map. Smalt was also mixed into the leadtin yellow paint of his shawl (visualized in the tin L-line map, Fig. 2e, and dark red cluster in Fig. 3c), as well as in some of the darker areas in his right shoulder (confirmed in paint cross-sections). Although Homer is seated, his chair can be hardly distinguished from the now brown cloak as a result of paint degradation. The curved bars of the chair, however, clearly show up in the lower left of the Co map. These are the dark passages low in $\mathrm{Co}$, that contrast with the light passages of his cloak, high in Co, that are visible in between the bars (cyan cluster in Fig. 3b). Smalt is also used in the shadow tones of his left hand, in the irises of his eyes, in the shadow side of his face, as well as in his hair and beard (yellow cluster in Fig. 3b). In contrast to the figure of Homer, the brown background is less rich in smalt.

The lead L-line map (Fig. 2d) reveals Rembrandt's expressive working manner in the light areas of Homer's face and slightly raised right hand. Here broad brushstrokes of thickly applied lead white paint, finished with pink and yellow tints, were applied over a brown underlayer that is partly left exposed. The lively gray brushstrokes of his hair and beard also show up in the $\mathrm{Pb}$ map (orange cluster in Fig. 3c). Most striking are the highlights of the golden shawl. Visible in both the $\mathrm{Pb}$ and $\mathrm{Sn}$ maps (Fig. 2e), a characteristic pattern of rectangular ridges in the lead-tin yellow containing paint testifies to the use of a palette knife (dark red cluster in Fig. 3c). Rembrandt only started to use a palette knife for the creation of bold surface relief in the 1650s [33]. The $\mathrm{Pb}$ map also reveals broad diagonal brushstrokes in a lead white-containing paint at the top of Homer's right sleeve that could be interpreted as highlights of folds in the cloak (dark yellow cluster in Fig. 3b). These are hardly noticeable in the visible light image, but suggest that the cloak was originally more detailed and voluminous than its present appearance suggests. The copper K-line map (Fig. 2f) shows its presence in the area of Homer's belt indicating the use of a copper-containing pigment, in addition to smalt (confirmed in cross-section, see Fig. 5d). The iron and manganese K-line maps (Figs. 2g, h) show the presence of iron and manganese in all the smalt paints, pointing to the admixture of earth pigments. The presence of calcium (calcium K-line map, Fig. 2i) can be associated with either chalk, bone black or the substrate of a yellow lake. The many losses in the painting, especially in the lower portion of the painting, were restored in 2005-2006 with chalk fillings, and retouched with earth pigments, also containing $\mathrm{Fe}, \mathrm{Mn}$ and $\mathrm{Ca}$. Normally these would be difficult to distinguish from original paint in the MA-XRF maps; however, they can be distinguished using t-SNE analysis (green cluster in Fig. 3d).

Differences in ratios of $\mathrm{Co}$ to $\mathrm{Ni}$, or Co to As, can point to the use of different batches of smalt with different ratios in the creation of the painting [17]. The Co:Ni scatter plot and ratio map (Fig. 4) suggest that a different smalt with slightly reduced $\mathrm{Ni}$ levels was used in Homer's undergarment, in the area just above his raised right hand. There was no paint cross-section from exact this location available to confirm this, but this may be worth investigating in the future. It would not be strange to find more than one source of smalt in this painting, since we know from documentary evidence that the painting was completed in two phases [12-14]. In 1661 Rembrandt sent a prepared canvas containing a painted sketch of the Homer to Ruffo's palace in Messina for approval. The sketch was sent back to Amsterdam at the end of 1662. In May 1664 Rembrandt sent the completed painting back to Messina.

\section{Paint cross-section analyses}

Cross-section analyses carried out in 2005-2006 revealed that the canvas is prepared with a double ground: a thick orangey lower ground containing chalk with some additions of earth pigment, followed by a greyish brown upper ground, comprising lead white (largely saponified) 

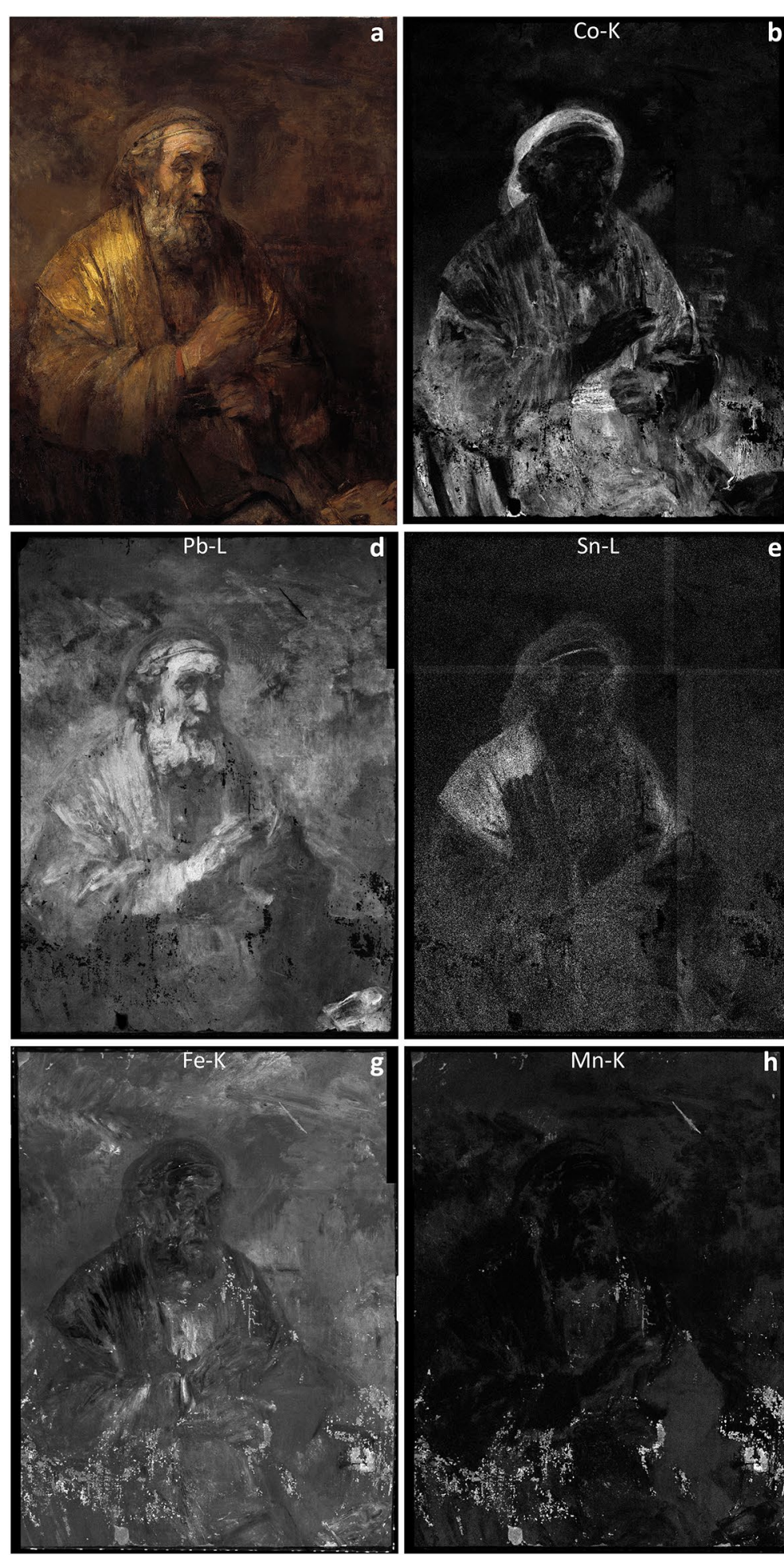

b

Co-K
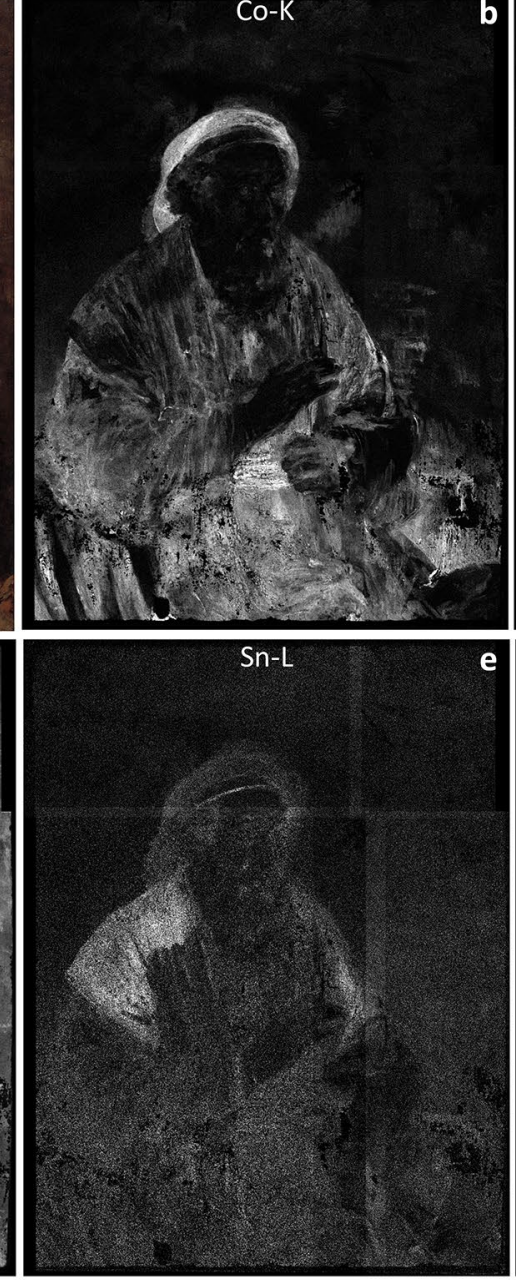

Sn-L

e

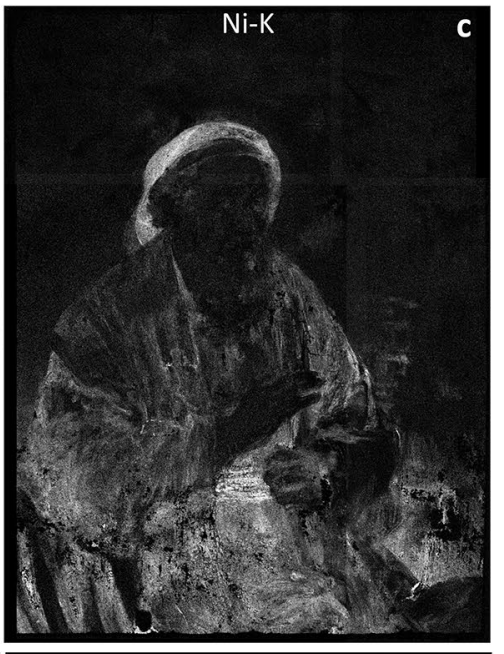

Cu-K

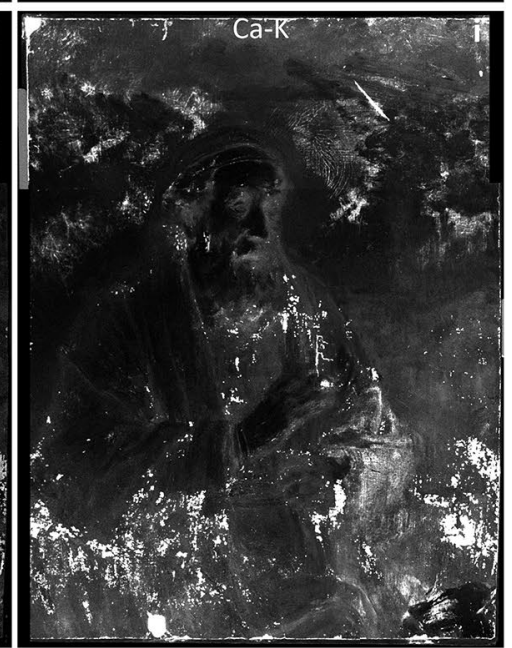

Fig. 2 Rembrandt van Rijn, Homer, 1663, oil on canvas (fragment), $107 \times 82 \mathrm{~cm}$, Mauritshuis, The Hague (inv. nr. Mh584). Visible light image (a), and corresponding MA-XRF maps: cobalt (b), nickel (c), lead (d), tin (e), copper (f), iron (g), manganese (h), and calcium (i) 

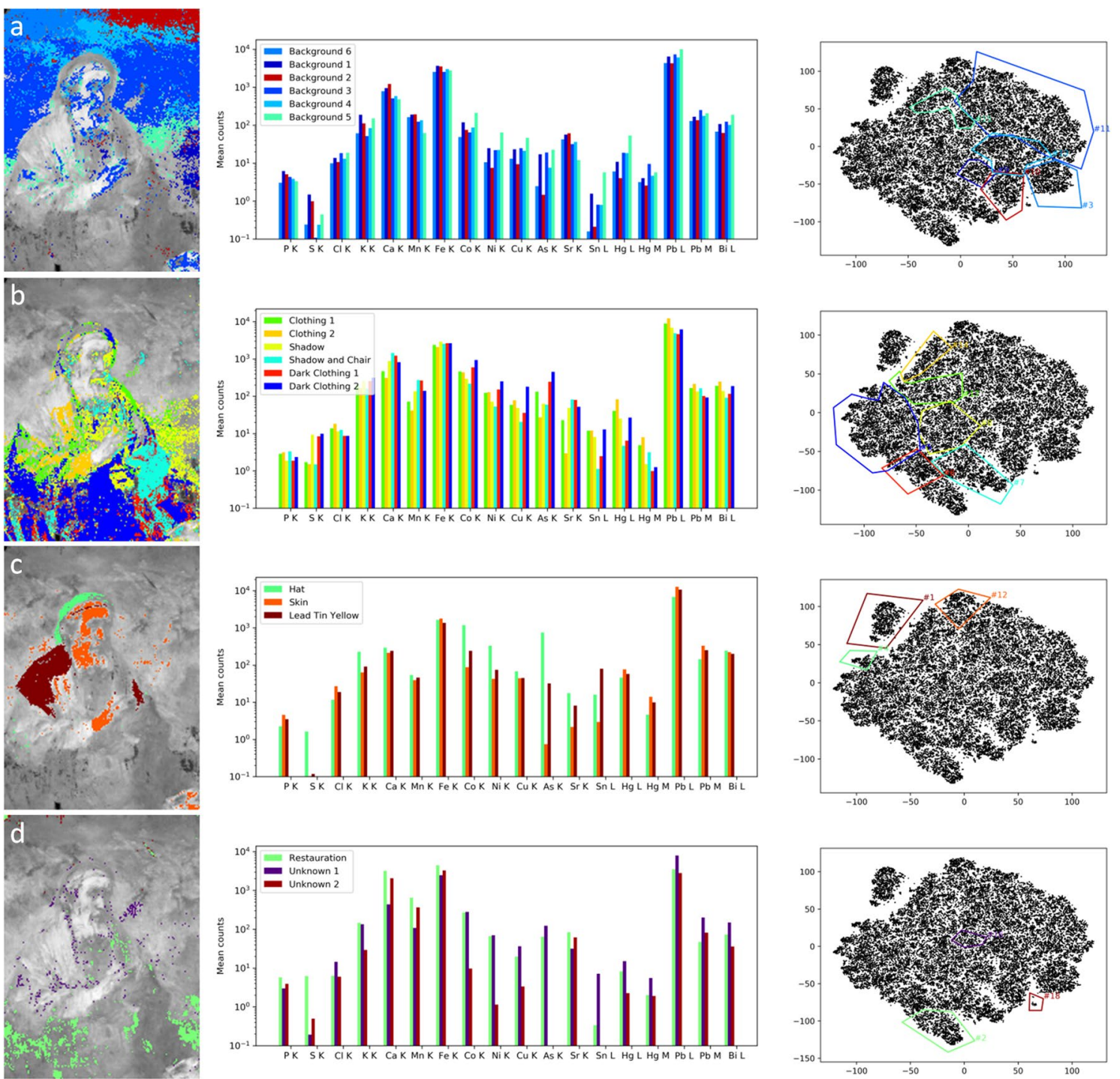

Fig. 3 T-SNE cluster analyses of the MA-XRF data showing the 18 clusters (a-d) as color projections on top of the Pb-L map (left), together with their spectral line intensities (middle), and tSNE plots (right)

with a little chalk, earth and black pigments [3]. On top of a dark brown painted sketch rich in Kassel earth, a thin fluorescing layer, possibly a resin varnish, is visible in many cross-sections when examined under ultraviolet light, which was probably applied before (or after) the painting was transported to Messina for the first time in 1662 to obtain Ruffo's approval. Cross-sections from Homer's garment confirm the presence of large amounts of a coarse smalt (variable particle size up to $40 \mu \mathrm{m}$ in diameter) in the upper paint layer(s). For this study we reexamined seven cross-sections of smalt paints from different parts of the painting, and analyzed their pigment compositions, which then formed the basis for the paint reconstructions (Fig. 1). Sample x06 from the cap shows that the smalt is mixed with yellow lake, bone black, and a little fine red and yellow earth (Fig. $5 \mathrm{a}-\mathrm{c}$ ). Based on the EDX map of silicon, and using software package ImageJ, we calculated that the smalt particles make up c. $30 \%$ surface area of the total paint layer. We did the same for the other pigments, and normalized these values to obtain the relative amounts of the different pigments, expressed as vol\% of dry pigment present in the paint: c. $60 \%$ smalt, c. $10 \%$ bone black, c. $10 \%$ yellow lake, c. $10 \%$ red earth and c. $10 \%$ yellow earth (Fig. 1). Samples from the belt (x25 and x34) even seem to contain a slightly higher proportion of smalt, namely c. $80 \%$ of the total pigment 

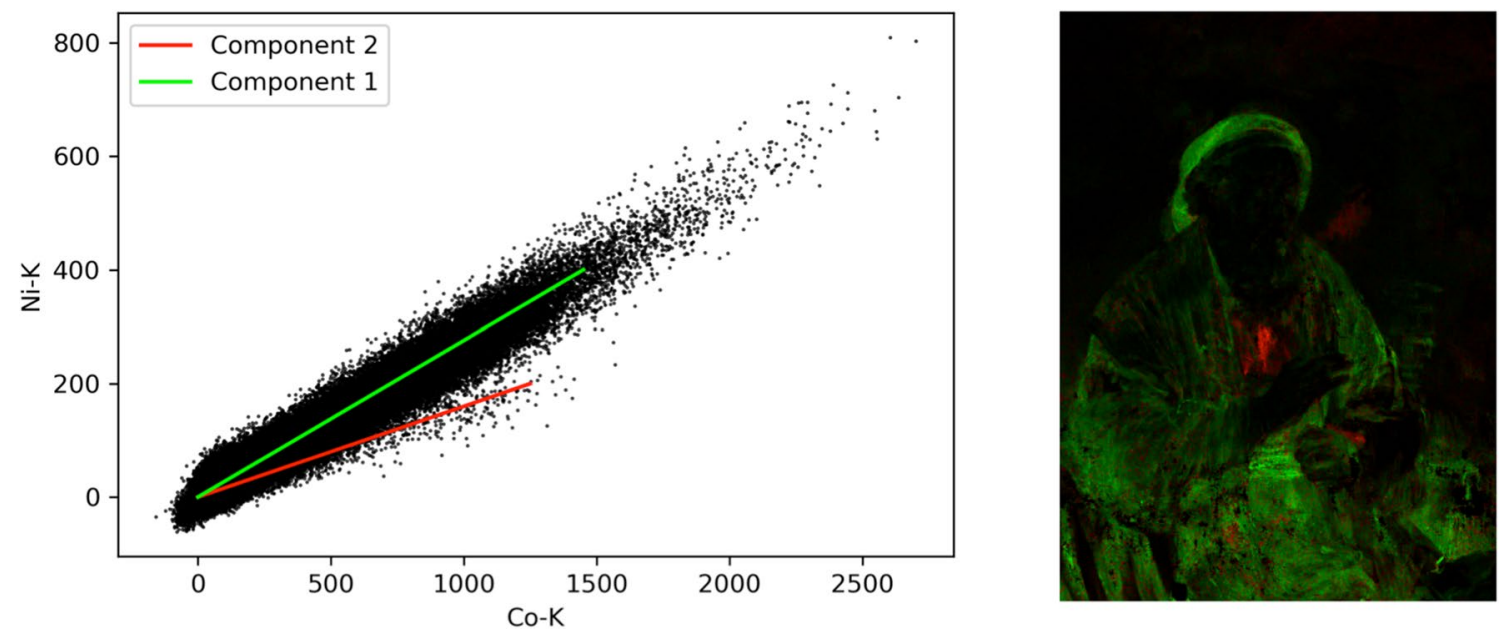

Fig. 4 MA-XRF Co:Ni scatter plot (left). The pixels of the cobalt distribution map are colored green (relatively higher Ni content) and red (lower $\mathrm{Ni}$ content) (right)

volume (Fig. 1). In sample x34 from the belt, several blue $\mathrm{Cu}$ particles, probably azurite, can be seen below the thick smalt-rich surface paint layer (Fig. 5d). This suggests that the belt was first laid in with a thin blue, azurite layer, after which it was finished with a thick smalt-rich paint (see XRF copper map, Fig. 2f). Samples x56 and x57 from the cloak show lower proportions of smalt, c. $50 \%$ of the total pigment volume (Fig. 1). As discussed in "MAXRF elemental distribution maps" section, the XRF maps of $\mathrm{Co}, \mathrm{Ni}$ and As show that the background paint is less rich in smalt. This is also supported by the paint crosssections from the background, which only show a few particles of smalt in the background paint. In sample $x 27$ we see two paint layers applied on top of the preparatory layers, separated by the thin varnish layer (Fig. $5 \mathrm{~g}-\mathrm{i})$. The surface or topmost layer in this sample, contains c. 50\% yellow lake, c. 15\% Kassel earth, c. 10\% bone black, c. 10\% red earth, c. $10 \%$ yellow earth, and only c. $5 \%$ smalt of the total pigment volume (Fig. 1).

\section{Quantitative analysis of smalt particles using SEM-EDX}

It is notable that almost all smalt particles in the crosssections from the painting appear pale or colorless. Only one particle is still blue. It shows a $\mathrm{K}_{2} \mathrm{O}$ content of c. $10.09 \mathrm{wt} \%$, while the $\mathrm{CoO}$ content has a value of c. 2.66 $\mathrm{wt} \%$, a common $\mathrm{CoO}$ content for seventeenth-century smalts. Spring demonstrated that a significant change in the quality of smalt used in North European paintings took place at end of the sixteenth century [34]. In smalts in sixteenth-century paintings, Spring measured a $\mathrm{CoO}$ content up to $9 \mathrm{wt} \%$, while high-quality smalts in seventeenth-century paintings were found to contain only c. 3 to $4 \mathrm{wt} \% \mathrm{CoO}$. By measuring the levels of potassium $\left(\mathrm{K}_{2} \mathrm{O}\right)$ in the smalt particles we could differentiate between well-preserved $\left(\mathrm{K}_{2} \mathrm{O} \approx 10-15 \mathrm{wt} \%\right)$ and degraded smalt $\left(\mathrm{K}_{2} \mathrm{O}<1 \mathrm{wt} \%\right)$, since the loss of color is related to potassium depletion. In this way it can be established whether a low grade of smalt (low $\mathrm{CoO}$ content) was deliberately used, or whether the pale or colorless particles are the result of discoloration. Quantitative analysis of the smalt particles illustrate that indeed a high degree of potassium depletion has taken place in the majority of the particles (Table 1). The measured $\mathrm{K}_{2} \mathrm{O}$ content varies between 0.30 and $0.89 \mathrm{wt} \%$, while the $\mathrm{CoO}$ $\mathrm{wt} \%$ is in the order of 3.02 to $3.61 \mathrm{wt} \%$, indicating that all the smalt particles have completely discolored. Note the small difference observed in $\mathrm{CoO}$ content between intact smalt (with high $\mathrm{K}_{2} \mathrm{O}$ ) and degraded smalt in Table 1. This is due to normalization of the total element composition to $100 \%$. The absolute $\mathrm{CoO}$ content does not change in degraded smalt. We did not observe a difference in $\mathrm{CoO}$ content between degraded smalt in samples from Homer's cap and Homer's garment, which both contain large amounts of smalt, and samples from the background paint that contain a smaller proportion of smalt, c. $5 \mathrm{vol} \%$ of the total pigment composition. The levels of arsenic, iron and nickel, introduced from the cobalt ore were also found to be consistent, which is in agreement with the Co:Ni scatter plots (Fig. 4). For the design of the paint reconstructions, $2.66 \mathrm{wt} \%$ was taken as starting point, and compared with reconstructions with $0 \mathrm{wt} \% \mathrm{CoO}$ and $4 \mathrm{wt} \% \mathrm{CoO}$ smalt $\left(\mathrm{K}_{2} \mathrm{O} \approx 16 \mathrm{wt} \%\right)$. 

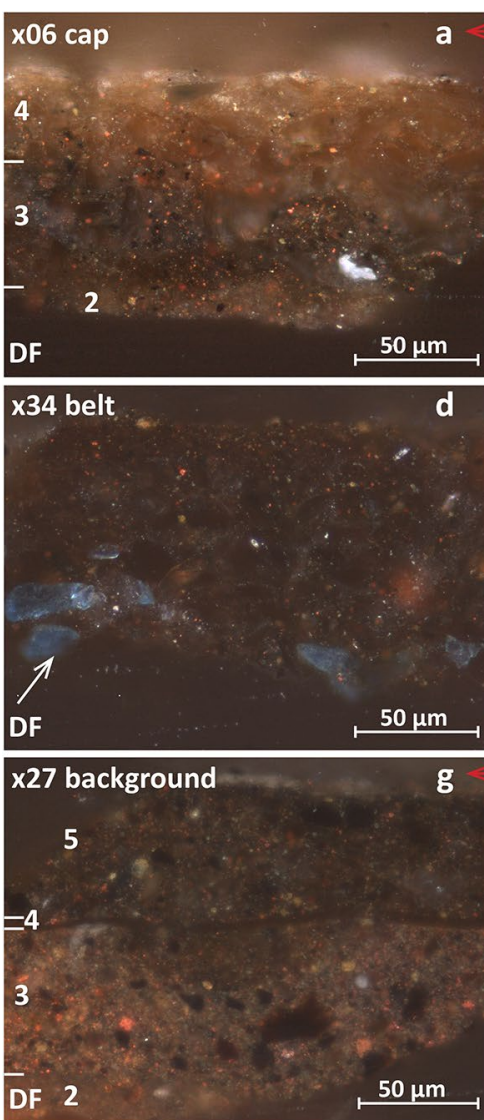
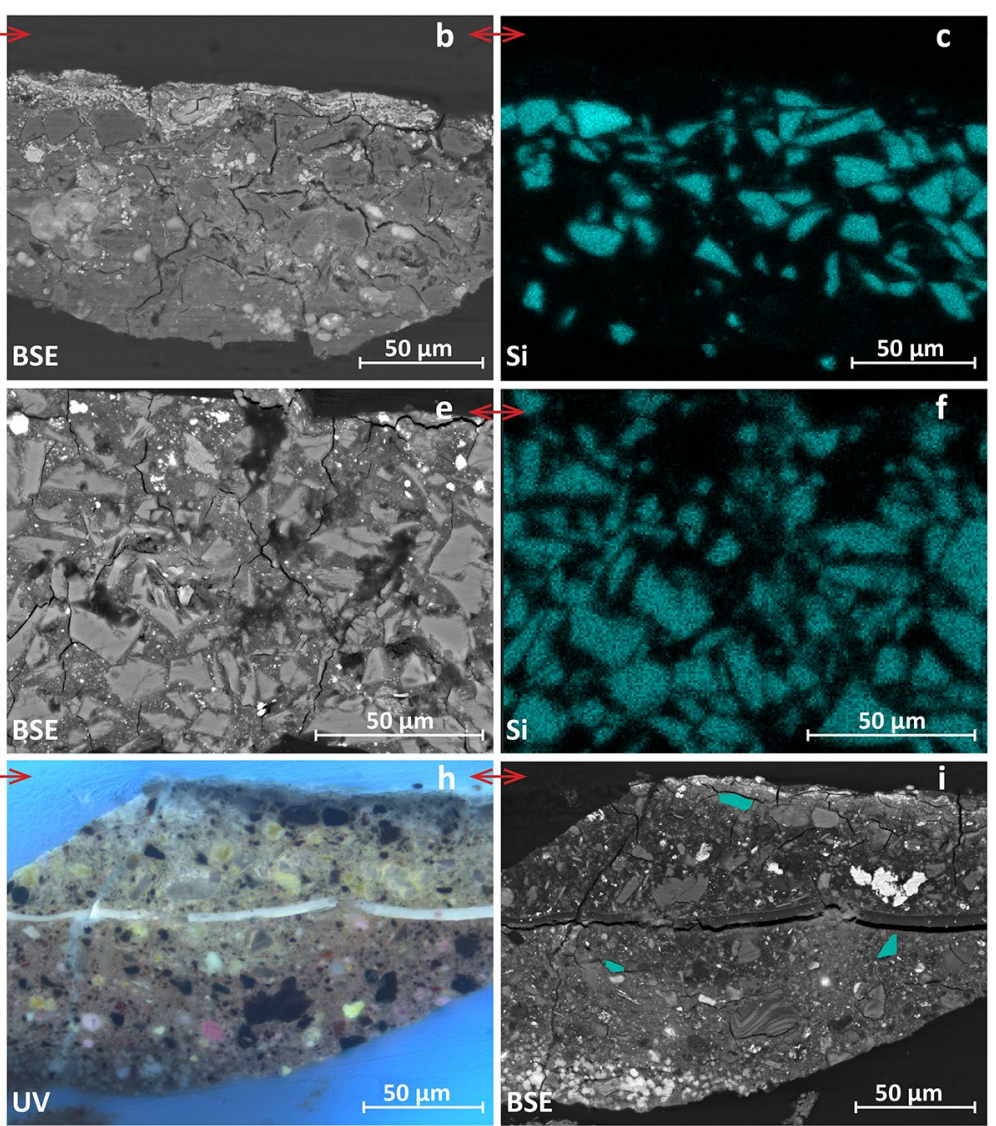

Fig. 5 Selection of paint cross-sections from Homer showing the abundant use of smalt. First row Sample x06 Homer's cap, light microscopic image, dark field (DF) (a), and corresponding SEM backscattered-electron (BSE) image (b), and EDX map of silicon (Si) indicative of smalt (c). The cross-section shows only the second greyish brown ground (layer 2), a dark brown sketch/undermodelling layer comprising bone black, earth pigments and some smalt (layer 3), and the surface paint containing a large amount of (now discolored) smalt, with additions of bone black, yellow earth, red earth and yellow lake (layer 4). Second row Sample x34 Homer's belt, DF image (d), BSE image (e), and corresponding EDX map of Si (f). e and $\mathbf{f}$ are from a different region than $\mathbf{d}$. The cross-section is incomplete (ground layers are missing), showing a single paint layer packed with (now discolored) smalt, with additions of bone black, yellow earth and red earth. Blue azurite particles (white arrow) are visible at the bottom of the layer. Third row Sample $\times 27$ right background, DF image (g), and corresponding ultraviolet (UV) image (h), and BSE image with smalt particles marked in blue (i). The cross-section shows the second greyish brown ground (layer 2), the dark brown sketch/undermodelling comprising organic brown (probably Kassel earth), bone black, yellow lake, red lake, red earth, yellow earth, with a few particles of smalt (layer 3), a thin intermediate varnish (layer 4), and the background paint containing yellow lake, organic brown (probably Kassel earth), bone black, red lake, yellow earth, red earth, and a few particles of smalt (layer 5)

\section{Paint reconstructions}

The reconstructions were made with historically appropriate materials that best matched the materials in the Homer painting. The aim was to assess the effect of different proportions of smalt on the visual, drying, translucency and textural characteristics of the paint.

\section{Effect on color}

To test the effect of smalt on the color of paint mixtures, we compared three different applications of the same smalt paint, each containing a smalt with a different cobalt content: $0 \mathrm{wt} \%$ (colorless glass), $2.66 \mathrm{wt} \%$ and $4.0 \mathrm{wt} \% \mathrm{CoO}$. This was done for all seven smalt paints shown in Fig. 1. In general, the paint reconstructions had a darker appearance and were more subdued/muted in tone than was anticipated. The blue color of the smalt was dominated by the admixture of the other pigments, even for smalt paints with proportions of smalt over $75 \%$ of the total pigment volume. Figure 6 displays the three different reconstructed paints applied on white and black tiles that correspond to the composition of sample x25 from Homer's belt (c. $80 \mathrm{vol} \%$ smalt). The $L^{*} a^{*} b^{*}$ values are digitally reproduced as color areas using Photoshop to visualize the observed differences. The left tile shows the paint reconstruction with colorless glass, the middle with the $2.66 \mathrm{wt} \% \mathrm{CoO}$ smalt, and the right tile with the $4 \mathrm{wt} \%$ 
Table 1 Results of quantitative EDX analysis of smalt particles in cross-section samples (in weight\% oxides and normalized to $100 \mathrm{wt} \%)$

\begin{tabular}{|c|c|c|c|c|c|c|c|c|}
\hline & $\mathrm{SiO}_{2}$ & $\mathrm{~K}_{2} \mathrm{O}$ & $\mathrm{CoO}$ & $\mathrm{Fe}_{2} \mathrm{O}_{3}$ & $\mathrm{As}_{2} \mathrm{O}_{3}$ & $\mathrm{Al}_{2} \mathrm{O}_{3}$ & $\mathrm{CaO}$ & $\mathrm{NiO}$ \\
\hline \multicolumn{9}{|c|}{ Sample x05 Homer's cap } \\
\hline Spot 1 (top layer) & 86.34 & 0.39 & 3.31 & 2.78 & 4.35 & 1.50 & 0.42 & 0.91 \\
\hline Spot 2 (top layer) & 81.91 & 0.48 & 3.26 & 3.37 & 6.81 & 2.43 & 0.78 & 0.97 \\
\hline \multicolumn{9}{|c|}{ Sample $\times 27$ background } \\
\hline Spot 11 (layer 3) & 80.36 & 0.79 & 3.14 & 4.48 & 4.47 & 3.28 & 2.93 & 0.55 \\
\hline Spot 12 (layer 3) & 79.83 & 0.89 & 3.02 & 2.86 & 6.92 & 5.24 & 0.81 & 0.42 \\
\hline Spot 8 (layer 5) & 86.55 & 0.13 & 3.11 & 2.86 & 4.27 & 1.59 & 0.74 & 0.76 \\
\hline \multicolumn{9}{|c|}{ Sample x58 undergarment } \\
\hline Spot 6 (layer 4) & 84.12 & 0.74 & 3.14 & 2.98 & 4.79 & 3.46 & 0.36 & 0.41 \\
\hline Spot 8 (layer 4/5) & 81.67 & 0.62 & 3.61 & 3.23 & 5.96 & 3.97 & 0.30 & 0.65 \\
\hline Spot 9 (layer 5) & 81.84 & 0.58 & 3.52 & 3.14 & 6.19 & 3.60 & 0.25 & 0.88 \\
\hline Spot 10 (layer 5) & 83.92 & 0.46 & 3.23 & 3.28 & 4.95 & 3.35 & 0.42 & 0.40 \\
\hline Spot 11 (layer 7) & 77.91 & 10.09 & 2.66 & 2.72 & 3.04 & 2.41 & 0.42 & 0.74 \\
\hline Spot 12 (layer 7) & 84.40 & 0.73 & 3.43 & 3.13 & 4.04 & 2.15 & 1.21 & 0.91 \\
\hline Spot 13 (layer 7) & 82.74 & 0.46 & 3.12 & 2.93 & 5.94 & 3.90 & 0.41 & 0.51 \\
\hline Spot 14 (layer 7) & 82.69 & 0.30 & 3.61 & 3.34 & 5.57 & 3.42 & 0.22 & 0.85 \\
\hline
\end{tabular}

CoO. The paint reconstructions with the colorless glass have a warm brown appearance. If we compare these to the middle and right tiles, which have a dark bluish grey appearance, it is clear that using a blue smalt makes the overall color of the paint cooler and darker in tone. The color difference between the 2.66 and $4 \mathrm{wt} \% \mathrm{CoO}$ smalt paints is hardly visible with the naked eye. Table 2 shows the $L^{*} a^{*} b^{*}$ values of the paint reconstructions based on the various samples from the painting. The smalt paint with the colorless glass $(0 \mathrm{wt} \% \mathrm{CoO})$ has higher $\mathrm{L}^{*}, \mathrm{a}^{*}$ and $b^{*}$ values than that the $2.66 \mathrm{wt} \% \mathrm{CoO}$ smalt paint, meaning the first is lighter, more yellow and more red in tone. The differences in $\mathrm{L}^{*} \mathrm{a}^{*} \mathrm{~b}$ * values between 0 and $2.66 \mathrm{wt} \% \mathrm{CoO}$ smalt paints are significantly larger than those between the 2.66 and 4 wt\% CoO smalt paints. Thus, color measurements support observations with the naked eye. A similar effect was observed for the sets of paint reconstructions based on samples from Homer's garment (sample x56 and x57), although these have an overall browner appearance due to the presence of higher percentages of earth pigments and lakes (see Additional file 1, Paint reconstructions, Figs. S3, S4). The paint-outs based on samples from Homer's cap (samples x05 and $\mathrm{x} 06)$ have a dark green appearance, due to the higher percentages of yellow lake and bone black in these smalt paints (see Additional file 1, Paint reconstructions, Figs. $\mathrm{S} 1, \mathrm{~S} 2)$. The $\mathrm{CoO}$ content of the smalt has very little effect here. The paint-outs based on the sample from the background (sample x27) produced a warm brown hue (see Additional file 1, Paint reconstructions, Fig. S6). Here the amount of smalt present in the pigment mixture was too low to notice the effect of different $\mathrm{CoO}$ contents of the smalt.

\section{Effect on drying properties}

The same glass/smalt paint mixtures from the previous section, with 0, 2.66 and $4 \mathrm{wt} \% \mathrm{CoO}$, were also applied on Leneta Opacity Charts $(50 \mu \mathrm{m}$-thick films, see also "Design of the paint reconstructions" section in "Experimental"). Their drying was measured over a period of 6 days using the salt drying test ("Salt drying test" section in "Experimental"), and compared with the drying of the pure smalt paint films (2.66, $4.0 \mathrm{wt} \% \mathrm{Co})$ and the colorless glass paint films $(0 \mathrm{wt} \% \mathrm{Co})$ in oil. The graph displayed in Fig. 7 plots the amount of salt taken up during the drying of the paints over time. When the amount of salt taken up reaches zero, the paint surface is considered dry. This was confirmed by gently pressing in the paint with a finger. The pure smalt paints, as well as the smalt mixtures made up of $50 \%$ or more pigment volume of smalt, were fully dried within 1 or 2 days. The drying effect of the smalt was already measurable after $2 \mathrm{~h}$. There was no observable difference between the 2.66 and $4 \mathrm{wt} \% \mathrm{CoO}$ smalt on the speed of drying with the methods used. For the paint reconstructions with colorless glass, some degree of drying could be detected after 2 days, but it took 10 days before these films were fully dry. For the paint mixtures with very little smalt, c. $5 \%$ of the total pigment volume, the effect of smalt on the speed of drying was negligible. We also compared the drying of paint reconstructions made with pure yellow lake and the same paint to which c. $5 \%$ coarse smalt was added, 


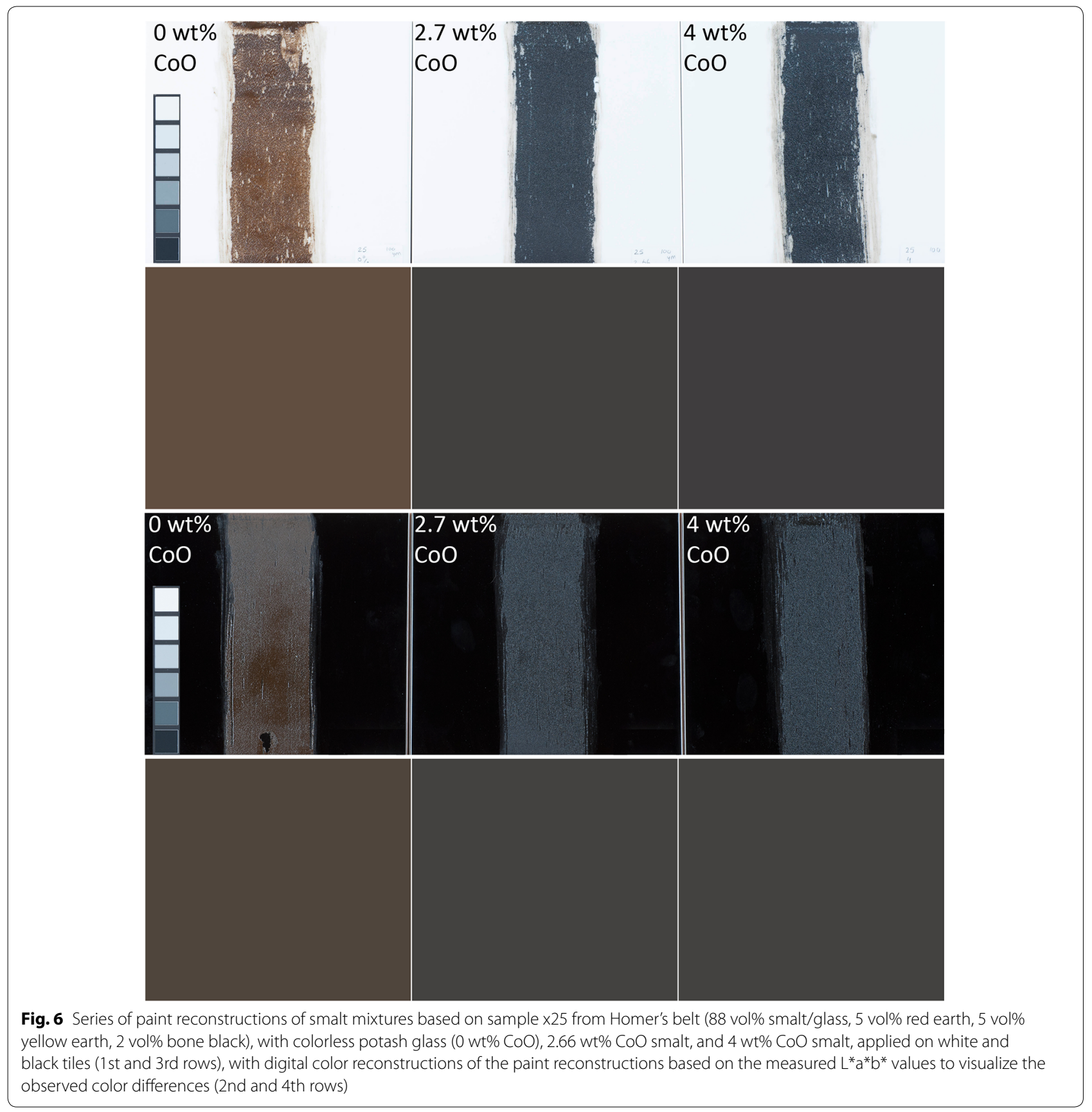

and did not observe any differences in drying time. Both paints needed 2 weeks before they had fully dried.

The drying tests demonstrated that only substantial amounts of smalt ( $>50 \%$ pigment volume) have a significant effect on drying times of the paint. It speeds up the drying by 5 times. In contrast, colorless glass containing only silica and potash, as well as very small amounts of smalt (c. 5\% pigment volume) did not show any significant effect on the drying time in our experiments. In her paper, Groen remarked that the particle size of smalt may have an effect on the speed of drying due to the catalytic action of cobalt that occurs in smalt at the interface between the pigment particles and the oil binding medium. She considered that drying is enhanced when the surface area is larger, hence with the use of smaller particles [1]. It is possible that with smaller particles, even small amounts of smalt may improve drying. This was not further explored in this paper. 
Table $2 L^{*} a^{*} b^{*}$ data of paint-outs applied on white and black supports. $\Delta L^{*} a^{*} b^{*}$ is calculated to be used as an indication of the translucency of the paint

\begin{tabular}{|c|c|c|c|c|c|c|c|c|c|}
\hline & \multicolumn{3}{|c|}{ On white support } & \multicolumn{3}{|c|}{ On black support } & \multicolumn{3}{|c|}{$\begin{array}{l}\text { Differences }(\Delta) \text { (e.g. } \\
\left.\Delta L^{*}=L^{*}{ }_{w}-L^{*}{ }_{z}\right)\end{array}$} \\
\hline & $L^{*}{ }_{w}$ & $a^{*}{ }_{w}$ & $b^{*}{ }_{w}$ & $L^{*}{ }_{b}$ & $a^{*}{ }_{b}$ & $\mathbf{b}^{*}{ }_{\mathrm{b}}$ & $\Delta \mathrm{L}^{*}$ & $\Delta \mathrm{a}^{*}$ & $\Delta \mathbf{b}^{*}$ \\
\hline \multicolumn{10}{|c|}{ Paint-outs with 2.7 wt\% CoO smalt, earths, lakes and boneblack in linseed oil } \\
\hline x5 cap & 24 & 1 & 3 & 25 & 1 & 3 & 1 & 0 & 0 \\
\hline x6 cap & 29 & 2 & 5 & 29 & 2 & 5 & 0 & 0 & 0 \\
\hline x56 garment & 26 & 4 & 5 & 29 & 4 & 6 & 3 & 0 & 1 \\
\hline x57 garment & 29 & 6 & 8 & 27 & 7 & 10 & -2 & 1 & 2 \\
\hline x25 waistband & 27 & 0 & 0 & 28 & 0 & 1 & 1 & 0 & 1 \\
\hline x34 waistband & 31 & 3 & 5 & 30 & 3 & 5 & -1 & 0 & 0 \\
\hline x28 background & 24 & 2 & 5 & 24 & 2 & 7 & 0 & 0 & 2 \\
\hline \multicolumn{10}{|c|}{ Paint-outs with 4 wt\% CoO smalt, earths, lakes and boneblack in linseed oil } \\
\hline x5 cap & 25 & 0 & 2 & 25 & 0 & 2 & 0 & 0 & 0 \\
\hline x6 cap & 29 & 2 & 5 & 29 & 2 & 5 & 0 & 0 & 0 \\
\hline x56 garment & 30 & 5 & 7 & 31 & 5 & 7 & 1 & 0 & 0 \\
\hline x57 garment & 30 & 6 & 7 & 29 & 7 & 8 & -1 & 1 & 1 \\
\hline x25 waistband & 26 & 0 & 0 & 28 & 0 & 1 & -2 & 0 & 1 \\
\hline x34 waistband & 30 & 2 & 4 & 28 & 2 & 4 & -2 & 0 & 0 \\
\hline x28 background & 23 & 2 & 5 & 25 & 2 & 5 & 2 & 0 & 0 \\
\hline \multicolumn{10}{|c|}{ Paint-outs with colorless glass, earths, lakes and boneblack in linseed oil } \\
\hline x5 cap & 25 & 1 & 2 & 25 & 1 & 2 & 0 & 0 & 0 \\
\hline x6 cap & 29 & 2 & 6 & 29 & 3 & 6 & 0 & 1 & 0 \\
\hline x56 garment & 32 & 6 & 9 & 31 & 6 & 10 & -1 & 0 & 1 \\
\hline x57 garment & 30 & 8 & 9 & 30 & 7 & 9 & 1 & -1 & 0 \\
\hline x25 waistband & 35 & 6 & 11 & 30 & 3 & 6 & -5 & -3 & -5 \\
\hline x34 waistband & 34 & 8 & 10 & 32 & 6 & 9 & -2 & -2 & -1 \\
\hline x28 background & 22 & 2 & 7 & 23 & 2 & 7 & 1 & 0 & 0 \\
\hline \multicolumn{10}{|c|}{ Paint-outs with pure pigments in linseed oil } \\
\hline Smalt $2.7 w t \%$ & 35 & 0 & -27 & 26 & 0 & 0 & 9 & 0 & 26 \\
\hline Smalt 4 wt\% & 31 & 9 & -37 & 24 & 0 & 1 & 7 & 8 & 36 \\
\hline Red earth & 37 & 24 & 19 & 37 & 25 & 18 & 0 & 1 & 1 \\
\hline Yellow earth & 48 & 20 & 42 & 49 & 20 & 40 & 1 & 0 & 2 \\
\hline Kassel earth & 24 & 1 & 3 & 25 & 1 & 2 & 1 & 0 & 1 \\
\hline Bone black & 17 & 0 & 2 & 17 & 0 & 3 & 0 & 0 & 1 \\
\hline
\end{tabular}

\section{Effect on translucency}

All paint reconstructions of the smalt paint mixtures were applied on both white and black tiles to assess the influence of the substrate on the final color of the paint. This was used as a measure of its hiding power, and thus the degree of translucency of the paint. Paint films of pure pigments were also applied on the white and black tiles, for comparison. The paint films containing pure red and yellow earth pigments showed hardly any difference in color value $\left(\mathrm{a}^{*}, \mathrm{~b}^{*}\right)$ and lightness $\left(\mathrm{L}^{*}\right)$, since these pigments are very opaque in oil medium. In contrast, the pure lake and smalt films appear almost black when applied on black tiles: an indication of their lack of hiding power and strong translucency in oil. Calculating the differences in $L^{*} a^{*} b^{*}$ values between the paints on the white and black tiles confirm these visual observations (Table 2). If we look at the values of the pure smalt paints, for example, we can see that those applied on the white tiles show a much higher $L^{*}$ value and a higher negative $b^{*}$ value than those on the black tiles $\left(\Delta \mathrm{L}^{*}=9\right.$; $\Delta b^{*}=26$ for $2.66 \mathrm{wt} \% \mathrm{CoO}$ smalt), demonstrating that they are lighter and less yellow and more blue in tone (see also Additional file 1, Paint reconstructions, Fig. S7). The pure earth paints show a difference in $L^{*} a^{*} b^{*}$ values of not more than 2 (Figs. S8, S9). The colors of the paint reconstructions of the smalt paint mixtures look 

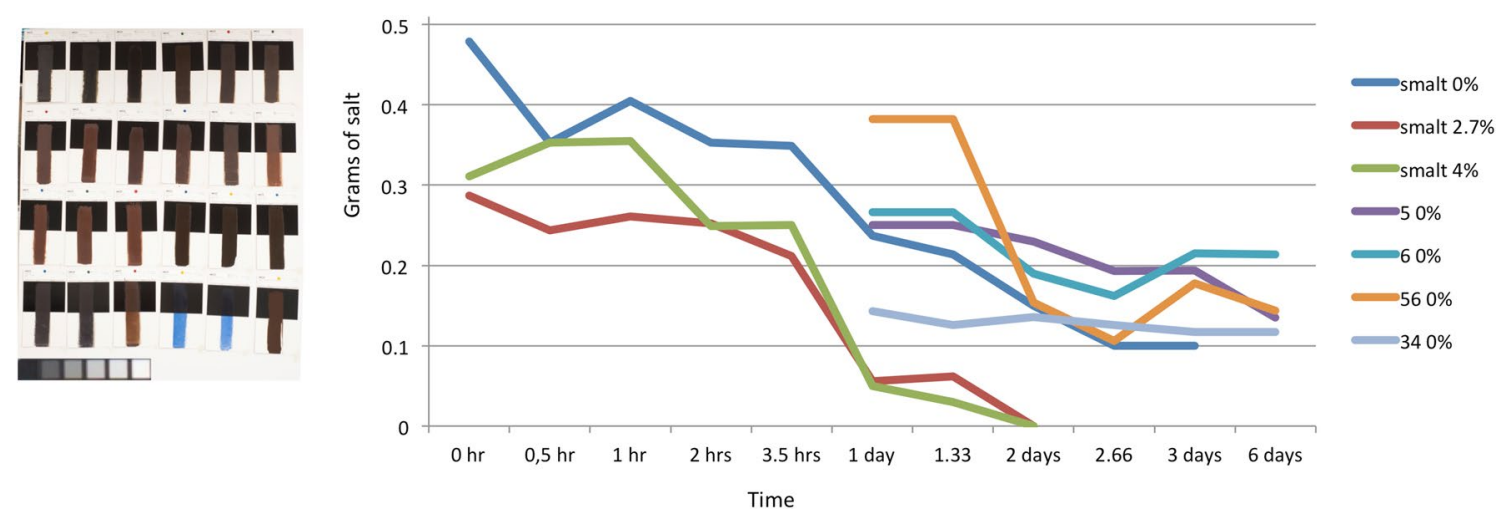

Fig. 7 Paint applications on black and white opacity charts for the drying tests (left), and graph showing the amount of salt taken up by the drying paints over time (right)

very similar when applied on a white or a black substrate, which corresponds with the small differences observed in L*a*b values (Table 2, see also Additional file 1, Paint reconstructions). Only some of the paint mixtures made with colorless glass, rather than blue smalt, show noticeable differences in appearance when applied on a white or a black tile. This was the case for the paint mixtures based on samples $\mathrm{x} 25$ and $\mathrm{x} 34$ that contain the highest proportion of smalt (c. $80 \%$ of total pigment volume). The color measurements demonstrate that, for example, paint reconstruction based on $\mathrm{x} 25$ with colorless glass is darker $\left(\Delta \mathrm{L}^{*}=5\right)$, less red $\left(\Delta \mathrm{a}^{*}=3\right)$ and less yellow $\left(\Delta \mathrm{b}^{*}=5\right)$, and therefore more green and more blue, on the black tile compared to the white tile. The slightly translucent paint mixture results in the effect that the black tile shines through the warm brown paint.

The above experiment shows that the presence of opaque earth pigments and bone black increases the hiding power of the smalt mixtures. It also makes them more opaque compared to paint reconstructions based on smalt and lake pigments. This might suggest that smalt has no effect at all. We observe, however, that the paint mixtures with substantial amounts of coarse smalt, produce richer, deeper colors when compared to the same mixture without smalt, or to paint films of pure earths (see also Fig. 8 discussed in the section below). This has to do with the large particle size of the smalt, which increases the heterogeneous character of the mixtures. Where these particles are exposed at the paint surface, light penetrates deeper into the paint. These differences are too subtle to measure with the colorimeter, but we could measure this effect to some extent with OCT (see "OCT measurements" section below).

\section{Effect on texture}

Figure 8 shows a series of five paint reconstructions with increasing amounts of smalt, from $0 \%$ to $75 \%$ of the total pigment volume, applied with a brush on canvas boards prepared with a white ground. A detail of the brushwork in the painting is also displayed for comparison (Fig. 8a). The first two paint reconstructions contain mixtures of equal proportions of yellow earth, red earth, and bone black, without smalt (Fig. 8b, c). When slightly diluted with a little extra oil, this mixture produces a very thin and smooth paint surface, in which the only discernible texture is the pattern of the canvas support below (Fig. 8b). The same mixture with a higher pigment volume concentration (not diluted with extra oil) creates a surface texture in which the lines made by the hairs of the brush become noticeable (Fig. 8c). When applying the $25 \%$ smalt paint, the brushstrokes become more pronounced, with sharp, standing ridges (Fig. 8d). This effect becomes even stronger with the $50 \%$ and $75 \%$ smalt paints (Figs. 8e, f). The $75 \%$ mixture is difficult to brush out. With the smalt mixtures it is possible to mimic the rough brushwork as observed in areas of Homer's garment (Fig. 8a). It was found that the paint mixture with $50 \%$ smalt came the closest to imitating the texture of the brushstrokes in the painting.

\section{OCT measurements}

OCT B-scans of $1 \mathrm{~cm}$ were performed on $100 \mu \mathrm{m}$-thick paint films of pure pigment applied on white tiles, and on mixed pigment paints based on the composition of sample $\mathrm{x} 34$ from Homer's belt (78 vol\% smalt/glass, 10 vol\% red earth, 10 vol\% yellow earth, 2 vol\% bone black). The upper left image of Fig. 9 shows the high-resolution depth profile of the pure smalt paint film $(2.66 \mathrm{wt} \% \mathrm{CoO})$ (Fig. 9a). The stratigraphy of the paint films is revealed as a result of differences in attenuation coefficient (AC), a 

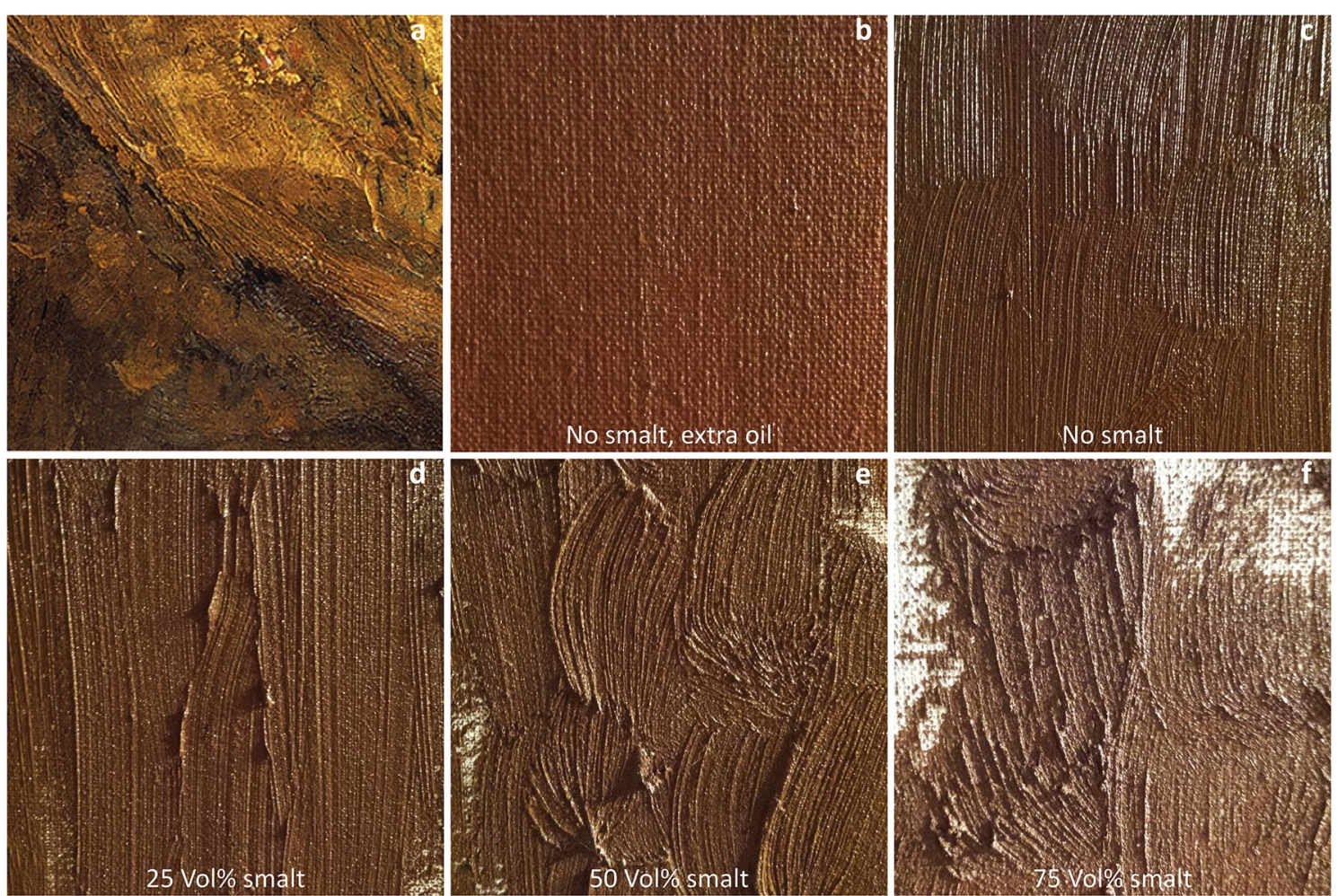

Fig. 8 Detail of brushwork in Homer's sleeve (a) and a series of paint reconstructions applied with a brush showing the effect of different volume percentages of smalt on the surface texture of the paint: mixture of red earth, yellow earth and a little bone black, diluted with oil (b), mixture of red earth, yellow earth and little bone black (c), same pigment mixture as (c) with 25 volume\% smalt (d), with 50 volume\% smalt (e), with 75 volume\% smalt (f)
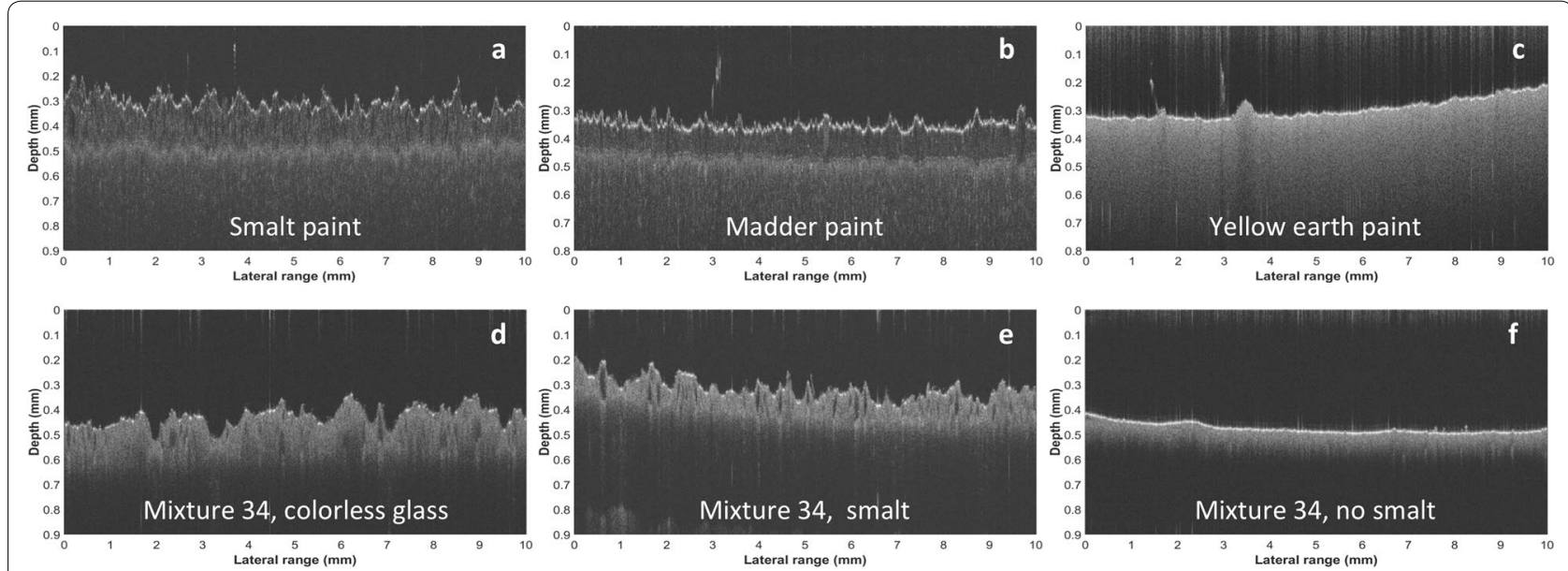

Fig. 9 OCT depth profiles of a series of paint films of pure pigments, and pigment mixtures based on sample x34 from Homer's belt (78 vol\% smalt/ glass, 10 vol\% red earth, 10 vol\% yellow earth, 2 vol\% bone black), showing the effect of a substantial amount of smalt on the translucency and surface topography of the paint: pure smalt paint $(2.66 \mathrm{wt} \% \mathrm{CoO})(\mathbf{a})$, pure madder paint $(\mathbf{b})$, pure yellow earth paint $(\mathbf{c})$, pigment mixture 34 with smalt $(2.66 \mathrm{wt} \% \mathrm{CoO})(\mathbf{d})$, pigment mixture 34 with colorless potash glass (e), pigment mixture 34 with no smalt added (f). Note that the depth axis of $\mathbf{a}-\mathbf{f}$ assumes that the refractive index is equal to 1 for all components within the sample. Therefore is represents the optical distance, and not the exact geometrical distance 
measure of how easily light penetrates through layers of a material. The jagged, upper white line marks the interface between the air and the smalt paint layer, revealing a corrugated surface topography. The second white line marks the interface between the smalt layer and the tile substrate. The images are cropped to discard non-relevant imaging artifacts. The fact that the paint-tile interface is visible in the depth profile demonstrates that the smalt layer is translucent and that light penetrates through the paint layer. This corresponds with the observations discussed in "Effect on translucency" section. The depth profile of the madder paint obtained with OCT also shows both interfaces, between that of the air and the paint, and between that of the paint and the tile (Fig. 9b), confirming that this paint is also translucent. The surface topography of the madder paint is less corrugated compared to the smalt paint. The depth profile of the yellow earth paint (Fig. 9c), however, looks very different than those of the smalt and madder paints. It shows strong multiple scattering at the interface between the air and the paint film indicating an opaque paint. The light does not have a deep subsurface penetration, and as a result the interface with the tile is not visible. The yellow earth paint film also shows a smooth surface topography.

The lower row of images in Fig. 9 compares the depth profiles of the mixed paints with colorless glass and blue smalt $(2.66$ wt $\% \mathrm{CoO})$, that make up c. $80 \%$ of the total pigment volume, and that of the same mixture without smalt (from left to right). The irregular surface topography of the colorless glass and smalt mixtures look similar (Figs. 9d, e) to that of the pure smalt paint-out (Fig. 9a). In these paint-outs the light only partly penetrates into the paint. It is notable that in the OCT images of the mixed smalt paint layers the smalt particles appear as dark cavities (Figs. 9d, e). It is also striking that these paint layers are only translucent up to where these dark cavities stop. No paint-tile interface is visible for Figs. 9d, e, as opposed to Figs. 9a, b. This is likely due to the fact that the optical scattering within the samples of Figs. 9d, e is higher than those of Figs. 9a, b, which must be the effect of the admixture of earth pigments and black to the smalt/glass paints. As expected, the depth profile of the paint reconstruction without smalt, shows a very opaque paint film with strong multiple scattering at the air-paint interface, and a very smooth surface topography (Fig. 9f). When compared to Fig. 9c, the absorption of the sample in Fig. 9f is much stronger, with otherwise similar multiscattering properties. This can be explained by the fact that the sample in Fig. If contains, in addition to earth pigment: bone black, which is carbon-based and absorbs in the (near) IR.

OCT proved a useful tool for visualizing differences in translucency (in near IR) and surface texture at a microscopic level. Where the colorimeter was not able to measure subtle differences in translucency within the paint, OCT was able to visualize the coarse grains of smalt in the paint, which are translucent in near IR (and therefore in OCT). Also the bulk of the paint is slightly more translucent in infrared.

\section{Art historical context of results}

The paint-outs described in the above experiments demonstrate that the addition of substantial amounts of coarse smalt provides texture to the paint, and, at the same time, reduces its drying time considerably. These effects are more significant than the color of the smalt itself. Although the smalt used by Rembrandt originally had a bright blue color, its hiding power was not very strong, and the other pigments present in the mixtures, in particular the yellow and red earths, dominate the color. The admixture of both yellow and red earths give the smalt paint a strongly muted, or-depending on the amounts-even a brownish hue (Fig. 8). Thus, the reconstructions support earlier assumptions that Rembrandt added smalt to his paints for reasons other than the color. The use of smalt to manipulate/modify the consistency of the paint fits with his late, experimental painting style, in which a deliberate variation in surface roughness of the paint-with rough brushwork in the foreground gradually changing to smoother paint towards the background-played a key role in the creation of threedimensionality and pictorial illusion [2, 33]. Rembrandt's late paintings also have a remarkable loose, sketchy character that gives them an apparent casualness, but which in fact makes them seem more realistic. In the eyes of his contemporaries, many of his late paintings were regarded as 'unfinished'. The many revisions that Rembrandt permitted himself during the painting process, even allowed for traces of the underlying paint layers to remain visible, which increased this naturalistic effect. That paintings executed in the rough manner had to be viewed from a distance, was also stated explicitly by Rembrandt [2].

Rembrandt employed several other techniques or 'tricks' to create paint relief, such as scratching into the wet paint with the back of his brush or his finger. His use of a palette knife or scraper to create texture, which leaves a rectangular pattern with raised ridges of paint due to the impression of the knife in the wet paint was remarkable [33]. This characteristic surface structure from the use of the palette knife is evident in the leadtin yellow highlights of the golden shawl on his right shoulder (Fig. 10b). The light reflecting from the raised ridges of paint enhances the brilliance of that passage. Also highly characteristic of the late Rembrandt are the bold broad brushstrokes of pastose (thickly applied) paint in the illuminated parts of Homer's face and his 

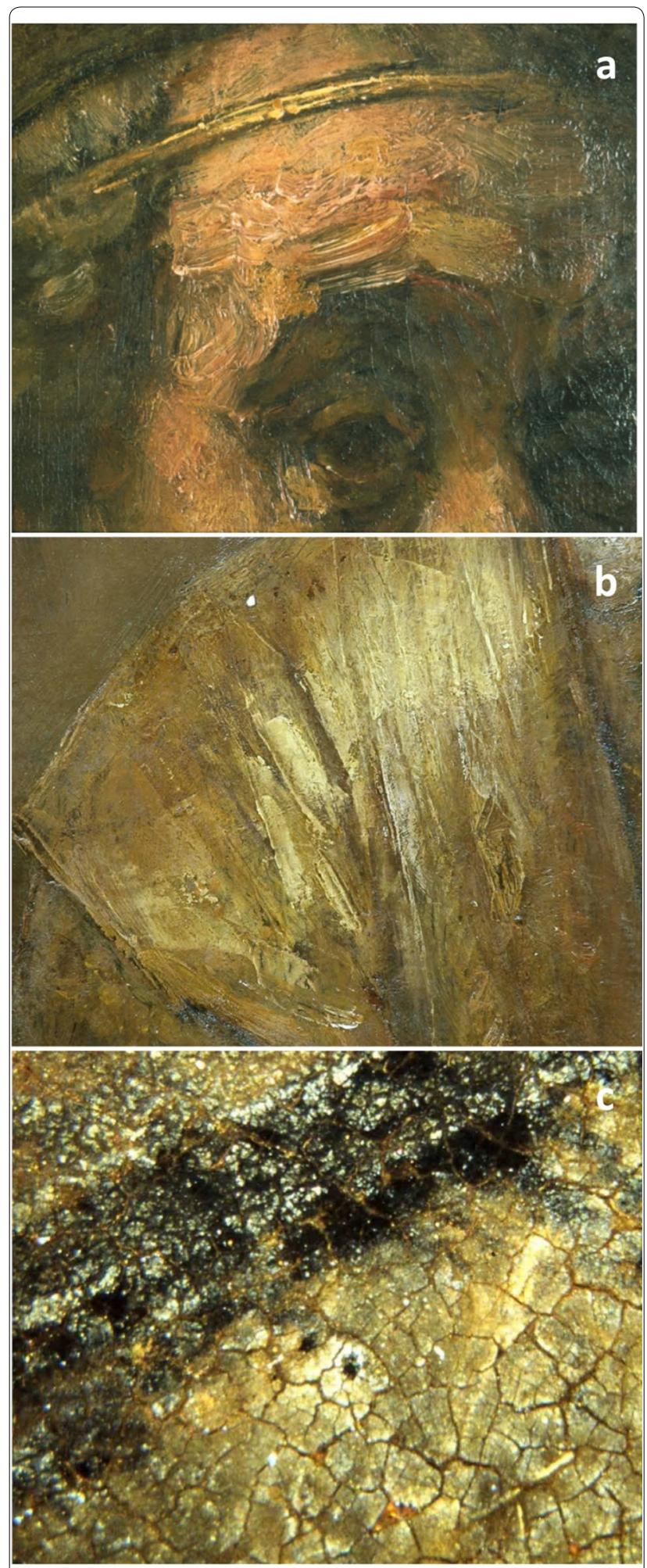

Fig. 10 Detail of Homer's face (a), and detail of yellow shawl on his right shoulder (b) showing strong paint relief. Stereomicroscope detail of Homer's garment showing the smalt paint covered with whitish surface crust (c) right hand (Fig. 10a). These areas are still very wellpreserved. Microscopic studies of paint cross-sections showed that the dense packing of fine particles and agglomerates gives lead white paint properties that allow it to 'stand up' three-dimensionally [1]. Rembrandt was a master in the application of lead white impasto paint, and many have wondered what he did to manipulate his lead white paint to obtain such desired effects. A recent study by Gonzalez et al. identified the presence of plumbonacrite $\left(\mathrm{Pb}_{5}\left(\mathrm{CO}_{3}\right)_{3} \mathrm{O}(\mathrm{OH})_{2}\right)$ in some of his lead white impasto paints. This is a degradation product (not an original paint component) formed under alkaline conditions, which might give a clue about how the paint was made [35]. We conclude that the use of smalt can be added to Rembrandt's unique repertoire of technical 'tricks' to modify the paint properties, specifically for the creation of sparkling texture and lively brushwork in (translucent) dark paints. In the reconstructions made as part of this study, the smalt paints that were applied with a brush show similar pronounced brushstrokes with raised ridges. In Homer, this effect has diminished over time due to chemical degradation of the paint, which has caused discoloration and the formation of whitish surface crusts (Fig. 10c).

Analysis of paint cross-sections shows that the smalt in Homer's paint is almost completely discolored. The paint reconstructions made with colorless glass also give clear indication of the impact of the discoloration of smalt on the appearance of the paint. The shift in color to warmer, browner tones compared to the paint-outs with blue smalt is also reflected in what we see in many of Rembrandt's late paintings (Fig. 6). Due to aging and ongoing chemical degradation, discolored smalt paints potentially become even browner due to the formation of potassium soaps in the paint matrix [6]. For Rembrandt's Homer this implies that his garment was originally cooler in tone, and that there was originally a greater distinction with the translucent dark brown background and the chair. Small color nuances and transitions in the garment are now also lost, which to some degree compromises the painting's three-dimensionality, as well as the overall spatial and pictorial illusion of the painting.

\section{Conclusions}

Non-invasive imaging with MA-XRF revealed the abundant use of smalt in Rembrandt's Homer, in areas that are now a monochrome brown. Complementary paint sample analysis demonstrated that the smalt was originally blue, and not a colorless glass, but has now almost completely discolored. It was used in mixtures with organic lakes, earth pigments and bone black. Although individual particles of smalt have degraded and are no longer blue, the effect of the overall paint color (which 
is a mixture of multiple pigments) is more subtle than what happens with a single smalt particle. By making paint reconstructions, we reproduced different versions of brown/dark paint, but cooler in tone. We were able to confirm earlier hypotheses that the late Rembrandt added large amounts of smalt to his dark paints, not to create blue colors, but most importantly to provide texture, using pronounced brushstrokes. The addition of substantial amounts of smalt also deepens the colors and makes the paint dry faster. Smalt can be added to Rembrandt's unique toolbox of tricks to manipulate the properties of the paint.

The conclusions regarding the role of smalt in this painting is an important step forward in gaining a better understanding of how complex pigment mixtures with smalt originally may have looked, and if they were meant to be brown. This was one of the initial research questions of the REVISRembrandt project. It is outside the scope of the project to make a complete (digital) reconstruction of the original appearance of Homer, but that is what we ultimately aim for in the future, and where this research can make a useful contribution.

\section{Supplementary information}

Supplementary information accompanies this paper at https://doi. org/10.1186/s40494-020-00429-5.

Additional file 1. Paint reconstructions.

\section{Abbreviations}

MA-XRF: Macroscopic X-ray fluorescence imaging; OCT: Optical coherence topography; SEM-EDX: Scanning electron microscopy-energy dispersive X-ray analysis; t-SNE: t-Stochastic Neighbor Embedding.

\section{Acknowledgements}

The research took place as part of the Science4Arts REVISRembrandt project, co-funded by the Netherlands Organisation for Scientific Research (NWO) and the US National Science Foundation (NSF). The paint reconstructions were carried out by Diana de Man, as part of her Master thesis in Conservation \& Restoration (University of Amsterdam C\&R, 2014-2015). Her thesis supervisors were Annelies van Loon (paintings research scientist, Rijksmuseum, Mauritshuis, TU Delft) and Maartje Stols-Witlox (associate professor and coordinator MA Paintings, UVA C\&R). We are grateful to Kate van Lookeren (lecturer Glass and Ceramics, UvA (\&R) for her advice and supervision regarding the synthesis of the smalt pigment used for the paint reconstructions. We also thank Art Proaño Gaibor (RCE) for providing the raw linseed oil used for the reconstructions.

\section{Authors' contributions}

AvL light microscopic and SEM-EDX paint analysis, data interpretation related to Rembrandt's technique, design of the paint reconstructions, drafting manuscript; PN light microscopic paint analysis, data interpretation related to Rembrandt's technique, editing manuscript; DdM paint reconstructions, contributed to relevant parts of the text; MA MA-XRF data processing and computational analysis, contributed to relevant parts of the text; GVdS, KJ, JD collection of MA-XRF data; TC collection of OCT data, OCT data processing, contributed to relevant parts of the text. All authors read and approved the final manuscript.

\section{Funding}

The Science4Arts REVISRembrandt project was funded by the Netherlands Organisation for Scientific Research (NWO) and the US National Science Foundation (NSF).

\section{Availability of data and materials}

The datasets used and/or analyzed during the current study are available from the corresponding author on reasonable request. The datasets supporting the conclusions of this article are included within the article and its additional file.

\section{Competing interests}

The authors declare that they have no competing interests.

\section{Author details}

${ }^{1}$ Conservation \& Science, Rijksmuseum, Hobbemastraat 22, 1071 ZC Amsterdam, Netherlands. ${ }^{2}$ Royal Picture Gallery Mauritshuis, Paintings Conservation, Plein 29, 2511 CS The Hague, Netherlands. ${ }^{3}$ Delft University of Technology, Materials Science and Engineering, Mekelweg 2, 2628 CD Delft, Netherlands. ${ }^{4}$ University of Amsterdam, Conservation and Restoration, Johannes Vermeerplein 1, 1071 DV Amsterdam, Netherlands. ${ }^{5}$ AXES Research Group, University of Antwerp, Groenenborgerlaan 171, 2020 Antwerp, Belgium. ${ }^{6}$ ARCHES, University of Antwerp, Mutsaardstraat 31, 2000 Antwerp, Belgium.

Received: 7 May 2020 Accepted: 7 August 2020

Published online: 04 September 2020

\section{References}

1. Groen K. Investigation of the use of the binding medium by Rembrandt: chemical analysis and rheology. Zeitschrift für Kunsttechnologie und Konservierung. 1997;11(Heft 2):207-27.

2. Van de Wetering E. Rembrandt, The Painter at Work. Amsterdam: Amsterdam University Press; 2000.

3. Van Loon A, Noble P, Boon J. White hazes and surface crusts in Rembrandt's Homer and related paintings. In: Bridgland J, editor. Preprints ICOM Committee for conservation 16th triennial meeting, Lisbon, 19-23 September 2011. Almada: Critério - Produção Gráfica Lda (CD-ROM).

4. Noble P, van Loon A, Alfeld M, Janssens K, Dik J. Rembrandt and/or Studio, Saul and David, c. 1655: visualizing the curtain using cross-section analyses and X-ray fluorescence imaging. Technè, Special Issue Rembrandt: approches scientifiques et restaurations. 2012;35:36-45

5. Roy A. Studying Rembrandt's techniques at the National Gallery, London. Technè, Special Issue Rembrandt: approches scientifiques et restaurations. 2012;35:6-13.

6. Spring M, Higgitt C, Saunders D. Investigation of pigment-medium processes in oil paint containing degraded smalt. National Gallery Technical Bulletin. 2005;26:56-70.

7. Boon JJ, Keune K, van der Weerd J, Geldof M, van de Asperen Boer JRJ. Imaging microspectroscopic, secondary ion mass spectrometric and electron microscopic studies on discolored and partially discolored smalt in cross-sections of 16th century paintings. Chimia. 2001;55:952-60.

8. Robinet L, Spring M, Pages-Camagna S, Vantelon D, Trcera N. Investigation of the discolouration of smalt pigment in historic paintings by Co K-edge micro X-ray absorption spectroscopy. Anal Chem. 2011;83(13):5145-52. https://doi.org/10.1021/ac200184f.

9. Ainsworth MW, et al. Art and autoradiography: insight into the genesis of paintings by Rembrandt, Van Dyck and Vermeer. New York: The Metropolitan Museum of Art; 1982. p. 102-3.

10. Laurenze-Landberg C. The examination of paintings by Rembrandt with neutron autoradiography and a comparison of neutron autoradiography with scanning macro-XRF. Restaurierung und Archäologie. 2015;8:99-114.

11. Roy A, Kirby J. Rembrandt's palette. In: Bomford D, Kirby J, Roy A, Rüger A, White R, editors. Art in the making rembrandt. London: National Gallery Company Limited; 2006. p. 35-47.

12. De Vries AB, Tóth-Ubbens M, Froentjes W. Rembrandt in the Mauritshuis. The Hague; 1978. p. 166-77.

13. Giltaij J. Nieuws omtrent Ruffo en Rembrandt. Kroniek van het Rembrandthuis. 2005;1-2:46-9.

14. Noble P, Pottasch C, van der Ploeg P. Rembrandt- recent restorations. Mauritshuis Focus. 2006;19(3):9-30. 
15. Price SWT, van Loon A, Keune K, Parsons AD, Murray C, Beale AM, Mosselmans JFW. Unravelling the spatial dependency of the complex solid-state chemistry of $\mathrm{Pb}$ in a paint micro-sample from Rembrandt's Homer using XRD-CT. Chem Commun. 2019;55(13):1931-4. https://doi. org/10.1039/c8cc09705d.

16. Mühlethaler B, Thissen JS. In: Roy A, editor. Artists pigments, a handbook of their history and characteristics, vol. 2. Washington; 1993. p. 113-30.

17. Janssens K, van der Snickt G, Alfeld M, Noble P, van Loon A, Delaney J, Conover D, Zeibel J, Dik J. Rembrandt's 'Saul and David'(c. 1652): use of multiple types of smalt evidenced by means of non-destructive imaging. Microchem J. 2016;126:515-23. https://doi.org/10.1016/j.micro c.2016.01.013.

18. Van der Maaten L, Hinton G. Visualizing data using t-SNE. J Mach Learn Res. 2008;9:2579-605.

19. Liang H, Peric B, Hughes M, Podoleanu A, Spring M, Saunders D. Optical coherence tomography for art conservation and archaeology. In: Proc. SPIE 6618, O3A: Optics for Arts, Architecture, and Archaeology, 661805 (16 July 2007). 2007. https://doi.org/10.1117/12.726032.

20. Targowski P, Rouba B, Góra M, Tymińska-Widmer L, Marczak J, Kowalczyk A. Optical coherence tomography in art diagnostics and restoration. Appl Phys A. 2008;92:1-9. https://doi.org/10.1007/s00339-008-4446-x.

21. Cheung CS, Spring $M$, Liang $H$. Ultra-high resolution Fourier domain optical coherence tomography for old master paintings. Opt Express. 2015;23:10145-57. https://doi.org/10.1364/OE.23.010145.

22. Callewaert T, Dik J, Kalkman J. Segmentation of thin corrugated layers in high-resolution OCT images. Opt Express. 2017;25:32816-28. https://doi. org/10.1364/OE.25.032816.

23. Alfeld M, Vaz Pedroso J, Van Eikema Hommes M, Van der Snickt G, Tauber G, Blaas J, Haschke M, Erler K, Dik J, Janssens K. A mobile instrument for in situ scanning macro-XRF investigation of historical paintings. J Anal At Spectrom. 2013;28(5):760-7. https://doi.org/10.1039/c3ja30341a.

24. Solé VA, Papillon E, Cotte M, Walter P, Susini J. A multiplatform code for the analysis of energy-dispersive $X$-ray fluorescence spectra. Spectrochim Acta Part B At Spectrosc. 2007;62:63-8. https://doi.org/10.1016/j. sab.2006.12.002.

25. Alfeld M, Janssens K. Strategies for processing mega-pixel X-ray fluorescence hyperspectral data: a case study on a version of Caravaggio's painting Supper at Emmaus. J Anal At Spectrom. 2015;30(3):777-89. https ://doi.org/10.1039/c4ja00387j.
26. Alfeld M. https://sourceforge.net/projects/datahandlerp/. Accessed 6 May 2020.

27. Alfeld M, Pedetti S, Martinez P, Walter P. Joint data treatment for Vis-NIR reflectance imaging spectroscopy and XRF imaging acquired in the Theban Necropolis in Egypt by data fusion and t-SNE. Comptes Rendus Phys. 2018;19:625-35. https://doi.org/10.1016/j.crhy.2018.08.004.

28. Shimazu, Y. Chemical and optical aspects of appearance changes in oil paintings from the 19th and early 20th century. Ph.D. thesis University of Amsterdam; 2015. p. 27.

29. Kunckel J. Ars vitraria experimentalis oder Volkommene GlasmacherKunst. Hildesheim, Frankfurt; 1992 (reprint from the 1689 edition).

30. Kirby J, van Bommel M, Verhecken A. Natural colorants for dying and lake pigments, practical recipes and their historical sources. London: Archetype; 2014. p. 95-7.

31. Gardner, H A, Sward G G. Paint testing manual: Physical and chemical examination: paints, varnishes, lacquers and colors. Gardner Laboratory, INC. USA; 1962. p. 118.

32. Nassif NA, Cense B, Park BH, Pierce MC, Yun SH, Bouma BE, Tearney GJ, Chen TC, de Boer JF. In vivo high-resolution video-rate spectral-domain optical coherence tomography of the human retina and optic nerve. Opt Express. 2004;12(3):367-76.

33. Bikker J, Krekeler A. Experimental technique, The paintings. In: Bikker J, Weber GJM, editors. Rembrandt: The Late Works, Exhibition Catalogue. Mercatorfonds/Brussel: National Gallery Company Limited; 2014. p. 133-55.

34. Spring M, Kugler $V$, Bean S. Quantitative energy dispersive X-ray analysis of the blue pigment smalt. In: Meek NN, Cartwright C, Meek A, Mongiatti A, editors. Historical technology, materials and conservation: SEM and microanalysis. London: The British Museum/Archetype; 2012. p. 114-22.

35. Gonzalez V, Cotte M, Wallez G, Van Loon A, De Nolf W, Eveno M, Keune K, Noble P, Dik J. Rembrandt's impasto deciphered via identification of unusual plumbonacrite by multi-modal synchrotron X-ray diffraction. Angew Chem. 2019;58(17):5619-22.

\section{Publisher's Note}

Springer Nature remains neutral with regard to jurisdictional claims in published maps and institutional affiliations.

\section{Submit your manuscript to a SpringerOpen ${ }^{\odot}$ journal and benefit from:}

- Convenient online submission

- Rigorous peer review

- Open access: articles freely available online

- High visibility within the field

- Retaining the copyright to your article

Submit your next manuscript at $\boldsymbol{\nabla}$ springeropen.com 